\title{
A Video Based Intervention to Support Children's Social, Emotional and Mental Health
}

\author{
Zoe Stephens ${ }^{1}$, Charlotte Marie Jackson ${ }^{1} \&$ Will Cross ${ }^{1}$ \\ ${ }^{1}$ Educational Psychology Service, Cornwall Council, Cornwall, England \\ Correspondence: Zoe Stephens, Educational Psychology Service, St Austell, Cornwall, PL25 5DR, England. Tel: \\ 44-797-349-7053. E-mail: zstephens@cornwall.gov.uk
}

Received: January 16, 2018 Accepted: February 8, 2018 Online Published: February 24, 2018

doi:10.5539/jedp.v8n1p54 URL: http://doi.org/10.5539/jedp.v8n1p54

\begin{abstract}
The intention of Reflect as an innovative intervention was to enhance and highlight the building blocks of Five to Thrive (Kate Cairns Associates 2012: Respond, Cuddle, Relax, Play and Talk) and help pre-school setting practitioners see how applying more of these principles could support positive change in a child's behaviour. The report provides background, research and theory behind the approach and intervention, and explains why it was chosen in this situation. It gives a description of how it is delivered in practice, so that it can be reproduced.
\end{abstract}

Key findings suggest progress in 2 main areas; 1) children's behaviour, emotional literacy and self-regulation and 2) change in the practitioners' approach to managing behaviour, their perception and attitude towards the children. Results from ratings by parents and pre-school staff using a standardised measure of behaviour (Strengths and Difficulties Questionnaire), showed improvements in children's behaviour by decreased scores in behaviour difficulties sub-scales post intervention. The Overall Stress data from staff ratings combined scores for 4 difficulty measures (emotional, behavioural concerns, hyperactivity/inattention and peer relationships) showed that $4 \%$ of children were functioning close to the 'Average' band pre-intervention, compared to $50 \%$ post intervention. Furthermore, staff ratings showed significant reductions to the number of children scoring at the most concerning 'Very High' difficulties band; $67 \%$ pre-intervention compared to $29 \%$ post intervention. All children made progress against individually set learning behaviour goals.

Progress and usefulness of Reflect was also evidenced qualitatively from setting staff evaluations and perceptions of the workers who delivered the intervention.

Keywords: attachment, attunement, behaviour, coaching, connectedness, five to thrive, resilience, solution focused, Video Enhanced Reflective Practice (VERP)

\section{Introduction}

The Reflect intervention is an ongoing support programme which began in August 2015. Members of Cornwall Council's Early Year's Inclusion Service formed a working party and developed a bespoke, video-based intervention to support pre-school children with emerging Social, Emotional and Mental Health (SEMH) needs. Prior to this date there was a pilot study involving 5 children, which informed the practicalities and final structure of the intervention, now titled Reflect.

Five to Thrive is an attachment based approach to positive parenting which has been developed by Kate Cairns Associates (KCA www.kca.training). Early Years Inclusion Service practitioners in Cornwall attended conferences where Kate Cairns presented this work in 2013, and these training opportunities have continued to be available to all practitioners in Cornwall through the training directory. Kate described her team's journey in developing the approach, which explains how and why a child's early experiences shape brain development. As part of the government's Early Years and Social Mobility agenda (Paterson, Tyler \& Lexmond, 2011), KCA were commissioned to provide an intervention to support healthy early brain development, based on the success of the Five a Day (healthy eating) campaign. Using research that had accumulated from neuropsychology and brain development in the previous decade on how early interactions and attachment figures can shape the growing infant brain; KCA arrived at Five to Thrive. Built on a similar concept that if five key activities or building blocks (rather than foods); Respond, Cuddle, Relax, Play and Talk are practised daily with a child, then there is a high probability that this will promote healthy brain development which will lead to greater emotional attunement with significant others and self- regulation. 
These five principles have been taught to parents and professionals working with and in child care settings and children's centres across the country (see Pettitt 2015 for a description of this roll out and evaluation of 2 projects by Barnado's). Many Early Years Foundations Stage (EYFS) practitioners in Cornwall attended the KCA conferences, providing the opportunity for them to apply the principles learnt in order to support parent/carers in their interactions with their children and also in the hope of impacting on their own practice and maximising the opportunity of providing secure secondary attachment figures to the young children in their settings. With a background in Solution Focused coaching, Video Interaction Guidance (VIG) and Video Enhanced Reflective Practice (VERP), members of Cornwall's Early Years Inclusion Service (EYIS) wondered how Five to Thrive could be effectively implemented in the county. Translating training experiences into practice can be difficult for practitioners (Stephens, Lee \& Wilde, 2007). To transfer new learning, develop skills and implement change are significant challenges, without follow up support such as that which a coaching model can provide. The practitioner's new knowledge (from the KCA conference) and subsequent online training in Five to Thrive had potential impact for the children in their care, especially those whose behaviour was causing concern. At that time there had been a noticeable increase in referrals to the EYIS for children with SEMH difficulties and some children were at risk of exclusion from their pre-school settings. There had also been an increase in the number of children excluded from school during their Reception year. Therefore it was agreed by senior managers in Cornwall Council that there would be an investment in Five to Thrive for staff from childcare and preschool settings and the development of an intervention to help embed the programme focused on the needs of children identified at risk of SEMH difficulties. The following report details the introduction of a novel approach by the EYIS in 2015 named 'Reflect: A Five to Thrive based intervention'.

\section{Background}

\subsection{Focus on SEMH}

The SEMH needs of pre-school children are essential to consider when following the Department for Education's (DFE) 2015 Early Years Foundation Stage (EYFS) framework and in accordance with the DFE's Special Educational Needs and Disability (SEND) Code of Practice (2014, later revised 2015). Changes to the EYFS in 2015 had already placed a greater emphasis on positive relationships, self-confidence and managing feelings and behaviour. Under the broader description of Personal, Social and Emotional Development (PSED) they form one of the Prime Areas of Development in the EYFS. Changes to the SEND Code of Practice (2015) included the need to provide early action to improve outcomes for children with SEMH needs.

Potentially difficulties in these areas may impact on children's ability to: engage in learning, (Durlak, Weissberg, Dymnicki, Taylor \& Schellinger, 2011) interact with their peers and develop a positive self-image (Heckman 2006). Prior to changes in 2014, the SEND code of practice included guidance on the group of children and young people described as having 'Behavioural, Emotional and Social Difficulties' (BESD). The emphasis of this descriptor was on behaviour rather than what may have been driving the behaviour. There followed a change to focusing on the SEMH needs of children and young people. This move has directed interventions away from behaviour management and towards developing prosocial skills and endorsing positive mental health and wellbeing, such as resilience building, self-regulation, emotion coaching and mindfulness.

In this report we have used the term PSED when describing children who are developing more typically and the curriculum for them. We have referred to SEMH in line with the SEND Code of Practice as the focus children in the study were experiencing significant difficulties with emerging Special Educational Needs (SEN).

\subsection{Why Are Attachment and the Development of Secure Relationships so Important in the Early Years?}

Behavioural indicators associated with SEMH difficulties clearly stem from unmet attachment needs. Case study narratives from psychiatrist Bruce Perry (2006) detail examples of how extreme behavioural changes can result from a lack or absence of early attachment relationships. Attachment is 'a deep and enduring emotional bond that connects one person to another across time and space' (Bowlby, 1969). A secure attachment relationship between a child and a primary caregiver can encourage the regulation of emotions and behaviour (co-regulation being a critical precursor for self-regulation) and promote feelings of confidence and self-worth. These in turn can increase the amount of positive interactions a child has with peers and other adults, thereby creating new relationships and friendships. As further work and research has progressed in this area, the idea of a single key attachment figure has been replaced by the realisation that a child can benefit and develop security and resilience through relationships with a number of significant adults, impacting on each individual and the development of their personalities throughout their whole lives. (Ainsworth \& Bowlby, 1991)

Neuroscience research has documented the sensitive periods of brain development within a child's first 3 years (Cozolino 2006), during which their brains are highly "affected by the environment and experiences that are encountered" Heckman (2006 p.1900) and also wired and programmed to handle stress and develop behavioural 
responses to adverse experiences (Schore 2001). During this period of development, repeated opportunity for co-regulation with adults helps to create the blueprint for self-regulation of many bodily functions including; sleep, appetite, temperature and stress control (KCA conference 2013). Our ability to self soothe and focus on the relevant features of any situation i.e. not overreact to potential threats, be in a calm, alert state and ready to learn are also key developments during this time (Sunderland, 2006).

Social and emotional skills such as self-regulation and stress management are therefore considered to be learnt through practise and rehearsal under guidance of supportive adults, just like other skills such as walking and talking (Siegel \& Bryson, 2012). When children do not develop this positive blue print in their crucial earliest years of life, there is a risk they will neither reach their learning potential nor maintain good mental health.

A critical or sensitive period (whether in utero, first 2 years of life or during adolescence) does not mean that brain wiring is fixed or that connections cannot be re-learned outside of that time frame. The brain has a certain level of plasticity. However it does mean that this is the optimal and most influential stage of brain development. Schore (2001) describes these first crucial years of life as specifically focused on development of the brain's right hemisphere, which is "centrally involved in processing social and emotional information, facilitating attachment functions and regulating bodily and affective states" as well as coping "actively and passively with stress". He proposes that experience of relationships can "positively or negatively influence the maturation of these brain structures" (p.10). Therefore a direct causal link between a child's early nurturing experiences and developing positive behaviour patterns was strongly suggested. This has been revisited and discussed frequently in more recent research and literature (Cairns, 2002; Siegel \& Bryson, 2012) and summarised in The 1001 Critical Days: "Science is helping us to understand how love and nurture by caring adults is hard wired into the brains of children" (Davies, 2013, p.2). The focus of this cross-party manifesto is intervention during the child's earliest experiences i.e. from conception up to a child's second birthday. However as behavioral indicators start to appear in pre-school children who have not had these optimal experiences, this can be taken as an indicator that further relationship based intervention may be needed.

Therefore an intervention to focus on positive interactions and enhance nurturing experiences for underachieving and frequently dysregulating preschool children appeared to be worth exploring.

\subsection{Risk Factors to Positive SEMH}

Developing the ability to self-regulate, achieve inner calm and learning readiness, are essential building blocks for a happy life. Conversely Masten and Cicchetti (2010) cite research linking poor academic achievement and social competence with depressive symptoms. The indications of a competency based model of depression are that SEMH difficulties and conduct problems in children have lasting effects and increase vulnerability to mental health difficulties in adults (Reading, 2013).

Neglect and negative experiences can harm the child by impacting on the development of secure and protective attachment relationships and in other ways. The Department for Health (2015) reports that Adverse Childhood Events (ACEs) affect the way the brain develops, and chronic stress alters brain, nervous system, hormonal and immune systems permanently. The brain may repair areas of damage to a certain extent e.g. after a stroke. However, stress impact and 'destructive emotions' (Goleman, 2004) have been associated with coronary disease and cancer. A longitudinal study by the Centre for Disease Control and Prevention (Felitti et al., 1998) which is part of America's Department of Health, gathered data in the 1990s which correlated ACEs such as abuse, neglect and dysfunctional home environments including divorce, domestic violence or a relative being imprisoned, with negative health and social outcomes.

Negative childhood experiences and trauma (including all forms of abuse) which effects brain development will therefore interfere with learning. The link between social deprivation and underachievement has long been apparent but not fully understood. This has been summarised by Wilshaw (2016) in a recent Ofsted publication. "Nearly half of the children from disadvantaged backgrounds have not secured the essential knowledge, skills and understanding expected for their age by the time they finish Reception Year. Around a quarter are unable to communicate effectively, control their own feelings and impulses or make sense of the world around them to ensure that they are ready to learn" (p.3).

It has been reported that 1 in 5 children each year will experience at least one ACE (Mcgee et al 2015). Children who have experienced more ACEs and / or who may have had less adult availability for co-regulation in their earliest years (including a higher proportion from disadvantaged backgrounds) may need additional support and targeted intervention in order to achieve better educational outcomes.

Displays of challenging behaviour in the preschool years can be a sign that early intervention is needed and that the child could benefit from better relatedness with key adults in their life, to build resilience and seek solutions in less negative ways. "Early interventions targeted towards disadvantaged children have much higher returns than later 
interventions" and "remedial skill investments" (Heckman 2006, p.1902). Interventions focused on providing solutions and developing resilience in practitioners and children, could act as an early intervention.

\subsection{Protective Factors and Intervention for Children}

The National Society for the Prevention of Cruelty to Children (NSPCC) carried out an evaluation of Video Interaction Guidance (VIG) an intervention using video with parents to help tackle neglect. VIG (Kennedy, Landor $\&$ Todd 2011) is a way of working with people using video feedback, to improve communication and interaction. It works by highlighting and drawing attention to helpful adult behaviours from video clips of 'better than usual' interactions. Selected video clips demonstrate; attunement, following the child's lead, responding to the child's initiatives and being fully present and responsive to the child. Whilst modelling these behaviours themselves, a VIG guider nurtures the parent in a relationship based therapeutic approach. The NSPCC found that parents reported significant change in the emotional and behavioural difficulties of their children by the end of the programme, including conduct problems such as temper tantrums, fighting with other children, disobedience, lying and stealing (Whalley \& Williams, 2015). Bakermans-Kranenberg, Van IJzendoorn, and Juffer, (2003) concluded from studies with parents and early infants that interventions with video feedback were more effective in developing attachment than those without.

One of the protective factors identified to counteract the impact of ACEs by the Department of Health (2015) was emotionally warm and positive relationships with close carers. Sensitive and attuned interactions with the adults around them, is protective for children against later SEMH difficulties developing. "The key issue in terms of all aspects of children's social, emotional, behavioural and cognitive functioning is interaction with primary caregivers" (Barlow 2014). What we now know about the importance of consistent relationships outside of the home including the impact of secondary carers indicates that in addition to working with parents, we have further opportunities to build resilience when children attend good quality childcare settings (Newman, 2004).

Child minders, nursery and preschool practitioners are well placed to develop secure relationships and help build resilience and positive emotional well-being during the early years. Masten and Gewirtz (2006) who have carried out research and extensive analysis of relevant literature in this area conclude that the "Early years hold great promise for interventions to prevent and reduce risk, boost resources, promote competence and build a strong foundation for future development." (p.1, 2013)

As a way of developing connectedness, adults need to be able to soothe and stimulate, and know when the child needs each of these through mentalizing (Shai \& Belsky, 2011) and feeling and seeing the world from the child's perspective. Approaches which help childcare and early education practitioners to do this and enable reflection and greater attunement to the child will therefore be beneficial. Herndon, Bailey, Shewark, Denham \& Bassett (2013) state that "Certain patterns of emotional expressiveness and regulation, support more mutually satisfying experiences with peers and adults in the classroom, which in turn facilitate children's greater attention to academic tasks, planning, and personal resources devoted to learning." (p.3).

The American Psychological Association's online Psychology Help Centre describes building resilience as "the ability to adapt well to adversity, trauma, tragedy, threats or even significant sources of stress" and that this can help to "manage stress and feelings of anxiety and uncertainty". When we are relaxed and our 'upstairs brain' (Siegel \& Bryson, 2012) is active, we are alert and in a ready-to-learn state, which is what children need, to be able to benefit from educational experiences.

In summary, there is a need to provide all children with security and positive relationships with key educational staff, with even greater emphasis to provide this support for vulnerable groups and those displaying early signs of SEMH difficulties. Availability of attuned adults is the key to emotional development, overcoming adversity and developing resilience. Kennedy, Ball, and Barlow (2017) describe how and why various video feedback techniques support infant attachment security within the context of parent and child. The proposal is that these same approaches can be beneficial in strengthening secure attachments between children and significant adults outside of the home, so adding protective relationships and helping to build resilience for vulnerable children. Masten, Best and Garmezy (1990) state that "Children who experience chronic adversity fare better or recover more successfully when they have a positive relationship with a competent adult," p425. Not all trauma and abuse will be avoided and so resilience building is a way to counteract or minimise its effects. Resilience skills can be learned (Moss 2016).

\subsection{Supporting Change and Professional Development}

Research suggests that quality pre-school provision is not always experienced by children in the most deprived areas. According to Ofsted judgements "In the most prosperous areas, only $8 \%$ of children are in early years provision that is less than good." and "For children living in the most deprived areas, this figure more than doubles, to $18 \%$ " (Wilshaw, 2016). By utilizing the benefits of video approaches to promote attunement and secure 
relationships, whilst also addressing possible variations in the quality of pre-school provision, the aim of this action research project was to increase children's resilience by supporting professional development of those working closely with them in childcare and preschool settings, using the tools and language of the Five to Thrive approach.

Strathie describes Video Enhanced Reflective Practice (VERP) as a method for "developing other professionals' interpersonal communication and learning" (Kennedy, Landor, \& Todd, 2015, p.170). VERP grew out of VIG and shares the same core values and beliefs, theoretical and psychological underpinnings and basic methodology. VERP uses video to explore moments of successful practice to promote growth and development, and self-motivated, self-owned learning. The VERP sessions occur within a supportive learning conversation following the Principles of Attuned Interaction and Guidance from VIG (Kennedy et al., 2011). Therefore VERP overlaps with coaching where an additional shared feature of goal setting and cycles of review of agreed actions are incorporated. Bandura (1986) developed the hypothesis that watching yourself perform a specific behaviour well, increases a sense of self-efficacy (the belief in your own ability to achieve). VERP showed potential for developing adult competency in the same way.

Fredrickson's Broaden-and-Build theory also explores the function of positive emotions in learning. Research shows that participants who experience positive emotions show heightened levels of creativity, flexibility, openness to new ideas and are better able to manage stress (Frederickson \& Branigan, 2005) Positive emotions "promote the discovery of people's strengths and resources, which serve as enduring reserves that can be accessed in times of need" (p11). When we are positive, supported and focused on what is going well, we are open to new ideas and learning, rather than defensive and resistant, which is how we can behave when told we need to do something better. Seeing something that we can already do well, even if initially this is only for exceptional moments in some cases, can help us to do more of what we have seen. Deciding for ourselves what we want to do better or more of, within the safety of a supportive learning conversation, helps us to dedicate ourselves to our preferred future and increases the likelihood of positive change. (See De Shazer 1985 for discussion of exception finding and preferred futures in Solution Focused thinking).

Kolb's cycle of experiential learning first published as part of Experiential Learning Theory in 1984 (Kolb \& Kolb 2007, p.8), describes how particularly adult learners, can enter at any of the 4 stages and will learn by following the cycle clockwise;

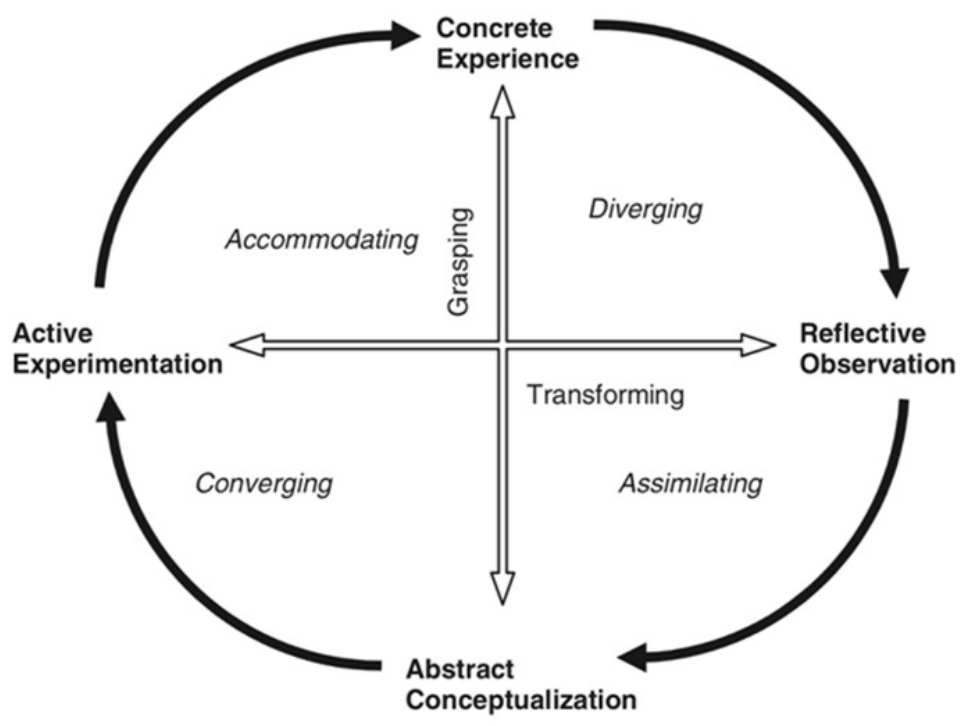

Figure 1 Experiential Learning Cycle

Often some support and guidance or reflective supervision is needed to move between stages of the learning cycle.

A life coach can help to "close the gap between thinking about doing and actually doing' (Martin, 2001, p. 5). In the situation of a child exhibiting challenging behaviour the parent / supporting adult / practitioner within a setting, may not yet be at the stage of thinking about doing anything or acknowledging their role in the solution i.e. that their behavior can have an impact on what they may perceive to be a within child problem. Conversely, applying a solution focused coaching approach, coaching is described as something which "creates the climate for individuals to examine their own strengths and to use them to achieve their goals" (Thomas \& Smith 2004, p31). Where the 
broad goal is to improve a child's behaviour, through the use of video to capture moments where the solution is already happening and exploring these with the learner 'reflective observation' can be enhanced. This process helps an attuned adult to see the positive impact they can have on another. An evaluation report published by the Education Endowment Foundation (EEF) in 2016 focused on a video technology system called IRIS Connect which highlights the potential of video reflective programmes; "emphasising the value of discussion that focuses on why a particular example of teaching might be engaging pupils in a particular way that is fostering their learning" (EEF 2016 key findings, summary of impact).

In the context of Reflect, the focus of teaching was within the Personal, Social and Emotional Development (PSED) strand of the EYFS. Behaviour is something that can be taught as much as literacy or numeracy and without this, arguably the corner stone of school readiness, there is likely to be a negative impact on academic learning.

Through learning conversations and planned cycles of goal setting and review (active experimentation) with solicited advice through a guider providing timely information sheets from the Five to Thrive KCA materials, it was anticipated that the Reflect intervention would enable adult learning and change in approach to be achieved.

Chinese philosopher Confucius famously said "I hear and I forget. I see and I remember. I do and I understand".

By supporting the hear (learning from the conference and KCA training), the see (from watching themselves on video) and the do (from the cycle of goal setting, trialing and review) the bridge between expert or new ideas and reality, leading to a change in practice could be achieved.

The aim of reporting on this study is to promote the value of video based approaches in supporting children's SEMH development, through changing the behaviour and attitudes of the adults who work with them most closely. It is written to enable the approach to be repeated in other settings and help commissioners and managers see the importance of staff development and supervision in relation to working with children who have SEMH vulnerabilities.

\section{Methods}

\subsection{Target Children}

Children were selected to receive Reflect according to the following:

- Children were selected between the ages of 24 and 59 months old and accessing an Early Year's setting

- Concerns were identified regarding the child's emotional responses and/or behaviour in their setting

- Children who were 'at risk' of exclusion from their setting

- Children noticed as being significantly withdrawn or isolated

- The child's emotional needs were perceived to be disrupting their access to and enjoyment with their play/learning environment to a significant degree and they had not responded to behavioural approaches and reasonable adjustments within the setting

- The relationship between adult(s) and the child had been affected by the child's challenging behaviour

- The child's current needs were indicated over both home and setting contexts

- The child's parent/carer(s) perceived that their child needed a higher level of intervention and support to access the EYFS.

Children who were considered to have a long-term developmental difficulty, medical diagnosis or high chance of future diagnosis i.e. Autism Spectrum Conditions, as the primary need were not usually included and were signposted to other support services. The initial decision for a child to be considered for the Reflect intervention programme was made by Cornwall Council's Senior Locality SEN Coordinator (SENCO) or Early Year's Educational Psychologist through either direct referral to the Early Years Inclusion Service and/or as a result of agreed actions during and following active casework observations and consultations.

44 children have received or are currently involved in the Reflect intervention. Of these children, $80 \%$ were deemed by the EYIW as being vulnerable or from disadvantaged backgrounds (linked to ACE descriptors based on information gathered by the EYIWs informally through engagement with parents and setting staff). To date, 31 have received the full intervention package. This evaluation summary is based on complete data sets for 24 of those children i.e. where all pre and post SDQ and Target, Monitoring Evaluation (TME) data was available.

Of these 24 children who received Reflect, the age of the children ranged from 31 to 52 months with an average age of 42 months at the start of the intervention. They included 20 boys and 4 girls and attended 18 different private, voluntary and independent (PVI) pre-school settings.

This work is part of an action research project and data continues to be gathered and analysed. This evaluation 
summary may be considered as stage 1 of the research.

Prior to the intervention being delivered, the EYIWs had received training in Five to Thrive, attachment and child development, solution focused thinking, coaching and had been participants in a VERP training and workshop programme.

\subsection{Measures/Data Collection}

Evaluation data from Early Years Inclusion Workers (EYIWs) who delivered the intervention, setting staff/practitioner qualitative accounts, EYFS tracking, SDQ pre and post scores from parents and setting staff and TME individual goal outcomes were collected. Both qualitative and quantitative measures were used.

\subsubsection{Strengths and Difficulties Questionnaire (SDQ) (Goodman, 1997) (see Appendix A)}

The SDQ is a brief behavioural questionnaire consisting of 25 questions over 5 different areas: emotional, behavioural concerns, hyperactivity/inattention, peer relationship difficulties and pro-social behaviour (being kind and helpful). Each question on the SDQ is rated as not true, somewhat true or certainly true and these ratings are translated into scores of between 0 and 2 . There are 5 questions for each of the 5 behavioural measures, giving a range of scores from 0 to 10 . For 4 of these 5 measures, a decrease in score post intervention is a positive change i.e. to reduce behavioural difficulties is the desired impact. For the final measure, pro-social behaviour, an increase in scores post intervention shows a positive change.

The SDQ was selected for use based on the following factors:

- It was originally designed for clinical practice but has also been used extensively within educational practice and social work

- It is relevant for assessing SEMH pertinent to Reflect

- The language used within the questionnaire is easily understood and accessible to wide populations, as it is downloadable in various languages

- The SDQ is less time consuming to complete and benefits from an online scoring system where summary reports can be quickly produced to ascertain differences between pre and post measures.

2 different versions of the SDQ were used. The parent 2 to 4 year old (pre and post) and teacher 2 to 4 year old (pre and post) and were completed before and after the video intervention, by the EYIWs and setting practitioners and EYIWs and the child's parent/carer(s). In analysis, the terms setting staff or staff are used instead of teacher as none of those involved held a teaching qualification.

\subsubsection{Target Monitoring Evaluation (TME) (Dunsmuir, Brown, Iyadurai \& Monsen 2009) (see Appendix B)}

TME's were used to identify a focus for the work and evaluate the progress for each child who received the Reflect intervention. TME's were agreed after the Early Years Inclusion Service's Senior Locality SENCO (SLS) had observed the child in the setting and before the intervention started. During a meeting between a SLS, EYIW, child's parent/carer(s) and setting practitioner, between one and 3 TME goals were agreed for the child and / or adults involved. At the end of the intervention the TME goals were reviewed by the same group and next steps agreed.

TME's provided interval level measurements on a scale of 0 to 10 . A baseline score was gathered at the initial meeting, with a description of what the current behaviour looked like, which could then be revisited and considered at the review stage. During the review meeting, progress was rated compared to the starting point to give a change in scale points.

\subsubsection{Video Clips}

Following the principles of VERP, two short video recordings (films) of the child and the practitioner interactions were taken: 1 at the start and 1 at the end of the intervention to look at the five key principles of Five to Thrive: Respond, Cuddle, Relax, Play and Talk. Following these recordings, the EYIW viewed the video recording with the practitioner; with the EYIW leading the conversation in an attuned way, with both identifying examples of where any or all of the five could be seen and recording these on the observation sheet (see Appendix C).

The video taken at the beginning of the intervention during session 1 helped inform which areas of practice for adult-child interactions needed strengthening. The second recording made at the end of the intervention in session 5 was used to further embed learning for the practitioner, help evidence improvement in the SEMH of the child, discuss and jointly assess the impact of the Reflect intervention and the changes that the practitioner had made.

Video recording was selected as a method over observations because of its impact on learning and process: to micro-analyse and revisit repeatedly to support practitioner's reflection and encourage them to consider the child's 
view.

\subsubsection{Early Years Foundation Stage (EYFS) (DfE, 2014) Tracking Information}

It was intended that data for all 17 areas (prime and specific) of the EYFS would be collected at the beginning of the intervention and 6 months after the intervention had been completed. As the data started to be analysed, anomalies arose, for example a variation in the PVI setting staff's use of the within phase of development descriptors (emerging, secure, developing) and a lack of pre intervention data for the Specific Areas of the EYFS due to the child's developmental stage at the start of the work. Also the child had sometimes changed settings i.e. started at school when the post intervention EYFS data was gathered and completion of this assessment by a different adult from a different setting, made this less reliable. Lastly, although a 6 month interval was planned, this post intervention data gathering period was inconsistent i.e. ranged from 4 to 10 months, again linked to change of circumstance and setting for the child (two children spent an extended period outside of the UK). Therefore it was decided not to include EYFS data in this report for the purpose of measuring impact of the intervention as it was deemed to be unreliable and incomparable. This will be discussed further in the conclusion and recommendations.

\subsubsection{Staff Summary Evaluation Questionnaire}

To gather post-intervention analysis and evidence of the Reflect intervention's impact for setting staff who participated and to consider possible spin offs for other staff in their settings, a staff/practitioner summary evaluation questionnaire was devised. This questionnaire featured 8 reflective questions (see Appendix D). At the end of the intervention, setting staff were asked to complete the questionnaire as a reflective exercise and give it to the EYIW or send anonymously to another member of the EYIS.

\subsubsection{Early Years Inclusion Workers (EYIWs) Summary Evaluation Questionnaire}

Following their involvement for approximately 2 years in developing and delivering the intervention, the EYIWs were asked a series of questions. These questions focused on gaining their perspective relating to the Five to Thrive programme key principles, goal setting and data gathering, learning and impact for all stakeholders including reflecting upon their own learning and their views on suggested improvements to the Reflect intervention for future delivery. This evaluation was completed in an open format where the EYIWs were able to read each other's responses and further develop them.

\subsection{Procedure for Current Study}

The Reflect research proposal was subject to ethical approval and gained clearance from Cornwall Council's Research Governance Framework panel.

Once parental consent had been gained, the SLS identified an EYIW to work with the key person from the setting to deliver Reflect.

SLS identifies child, checks against guidance and criteria and identifies EYIW to deliver the programme. Collects EYFS tracking data from the setting and gives to EYIW.

Information leaflet given to parent/carer and verbal consent gained by SLS. Leaflet/contract to setting and verbal consent also gained.

Pre-meeting with SLS, parent/carer, setting and EYIW. EYIW completes SDQ (1) pre with parent/carer and gets written consent. SLS sets up TME to include goals for child, setting and / or home. Set date for post intervention review meeting. 


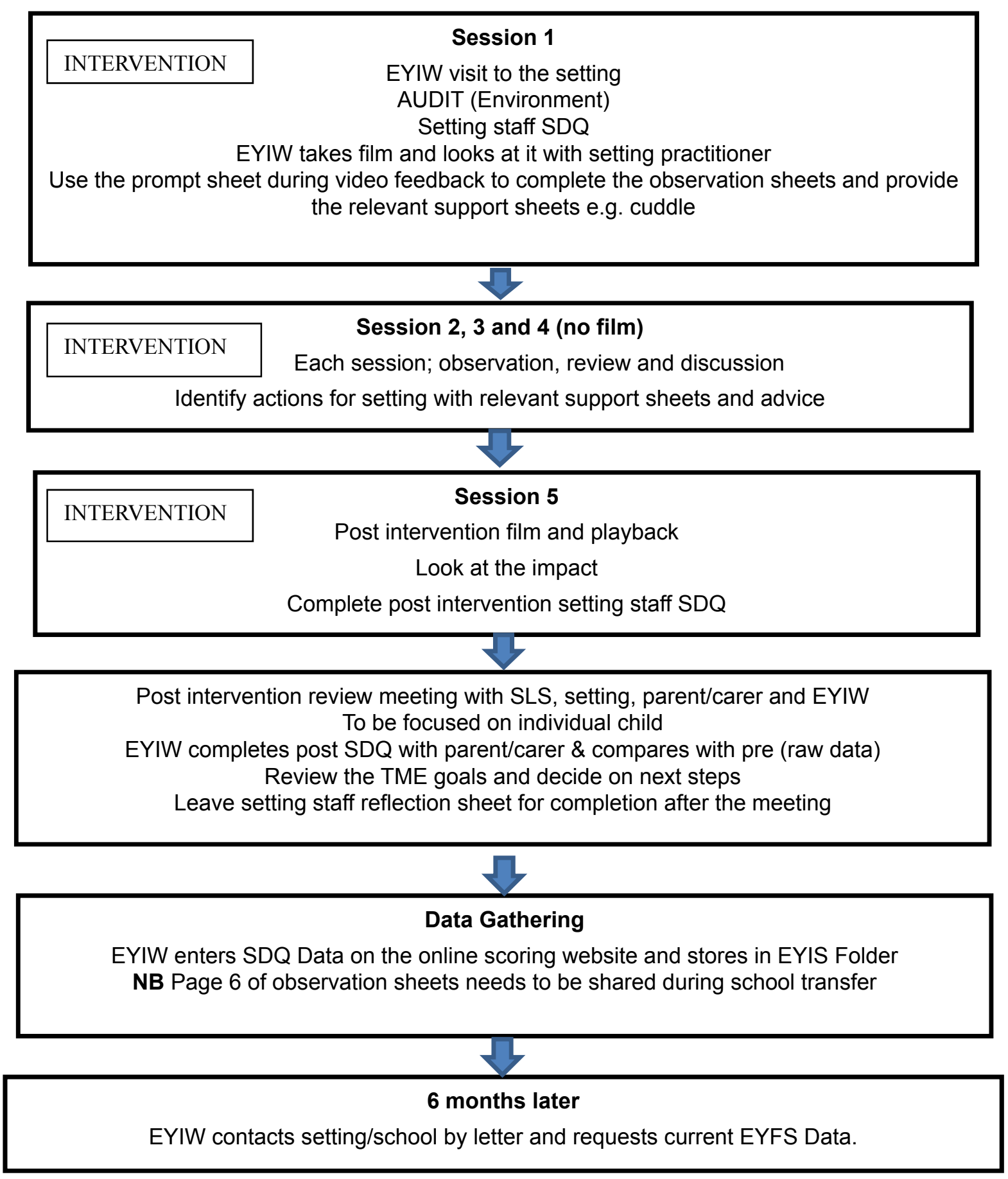

Figure 2. Flow Diagram to Show Structure of Reflect Intervention

Prior to the intervention, information was shared and gathered including completion of the parental SDQ and a meeting held with all key adults to establish the purpose and goals of the intervention.

An environmental audit (see Appendix E) was developed using aspects of the Self-evaluation Instrument for Care Settings (Laevers, et. al. 2005). This audit was used with setting staff to consider the elements that may lead to an enabling environment for the child to play and learn, such as access to resources, visual support systems and the layout of the room. Other areas included opportunities for the child to experience positive relationships with adults and to what extent the adult interacted and engaged with the child. This audit tool was used as part of the intervention and to promote setting staff reflections rather than as a pre and post comparative measure. 
During session 1 the EYIW and setting practitioner looked at the video together; first as an uninterrupted whole where the setting practitioner was encouraged to focus upon the 5 principles of Five to Thrive. The EYIW and the setting practitioner both made notes of their observations and shared their notes at the end of the first video analysis. Then the video was watched again and stopped at key moments when one or more of the 5 key principles were noticed. The EYIW guided the setting practitioner to reflect on what they had seen in the video clip that related to the key principles of Five to Thrive: Relax, Cuddle, Respond, Play and Talk and asked questions about how child and practitioner may have been feeling at that moment in the video. After watching and further micro-analysing the video, they agreed next steps on what the practitioner could do more of in their practice or introduce over the next weeks. Where relevant the EYIW shared a support sheet (from KCA resources - see Appendix F) with the setting practitioner for them to develop the agreed area or key principle from the Five to Thrive approach.

During sessions 2, 3 and 4 the EYIW returned to the setting and completed an observation of the child and setting practitioner and noted good practice in relation to the 5 key principles of Five to Thrive. Reflections and key points from the observations were then shared and discussed with the setting practitioner and agreed actions from previous sessions were reviewed and discussed, including;

- What the practitioner felt they had done differently or more of since the previous session

- What the setting practitioner felt the impact had been in relation to the differences in their practice

Next actions for the setting practitioners were agreed again at the end of each session. The EYIW shared further KCA support sheets and advice if a new Five to Thrive key principle was the focus of an agreed action.

During session 5 the EYIW visited the setting and filmed a second ten minute video. This was played back, reviewed, discussed and analysed by the EYIW and setting practitioner as in session 1. The practitioners post SDQ questionnaire was completed and the environmental audit was revisited.

A post intervention review meeting between the SLS, setting practitioner, child's parent/carer(s) and EYIW was held to evaluate the impact of the intervention and decide on next steps to support the child and in many cases, plan for transition to school. A report was written by the SLS including extracts from the observation sheets (p.6 summary of what has worked well to support the child - see Appendix $G$ for an example of this) and later included in transition plans for the child on starting school.

\section{Results}

\subsection{TME data}

\subsubsection{Analysis of Goals for Children}

Children had between 1 and 3 learning behaviour goals set which totalled 36 goals across the 24 children.

All 24 children showed improved TME outcomes in all of the goals set, where the changes from baseline scaling to outcome varied between 2 and 8 progressive points.

Table 1. Scale Point Progress for Children's TME Goals

\begin{tabular}{llllllll}
\hline & \multicolumn{2}{c}{ Some progress } & \multicolumn{2}{c}{ Good progress } & \multicolumn{2}{c}{ Extremely good progress } \\
\hline Amount of progress (points on 0-10 scale) & 2 & 3 & 4 & 5 & 6 & 7 & 8 \\
\hline Number of goals that progressed by this amount & 4 & 6 & 11 & 5 & 6 & 2 & 2 \\
\hline
\end{tabular}

Post intervention, 4 of the children showed extremely good progress according to the TME scale i.e. 7 and 8 progression points. Of these, 1 child was able to identify and name emotions, 2 were starting to self-regulate e.g. "he goes to throw things and stops himself" and 2 references were made to significantly reduced incidents of hurting and aggressive behaviour towards others.

\subsubsection{Nature of Goals}

TME goals set were linked to the best fit category or subscale of the SDQ.

The majority of goals set for children were aimed at improving getting along. This included themes from the peer relationship difficulties and Prosocial sub-scales, as they often overlapped.

Below are some examples of TME goals which were set.

Examples linked to getting along: 
'For A to use the term "shall we play?" (or similar) to start an interaction with another child.'

'B to take a series of turns with other children, supported by an adult.'

Examples from the emotional sub-scale:

' $C$ 's angry outbursts to reduce in frequency and severity at nursery.'

'D will express her emotions to the adult, particularly when feeling cross.'

Examples from the behavioural subscale:

'E to sit within a small group of children for a short, motivating story.'

' $F$ to come with the adult at group times and stay for 3 spots of the spot timer.'

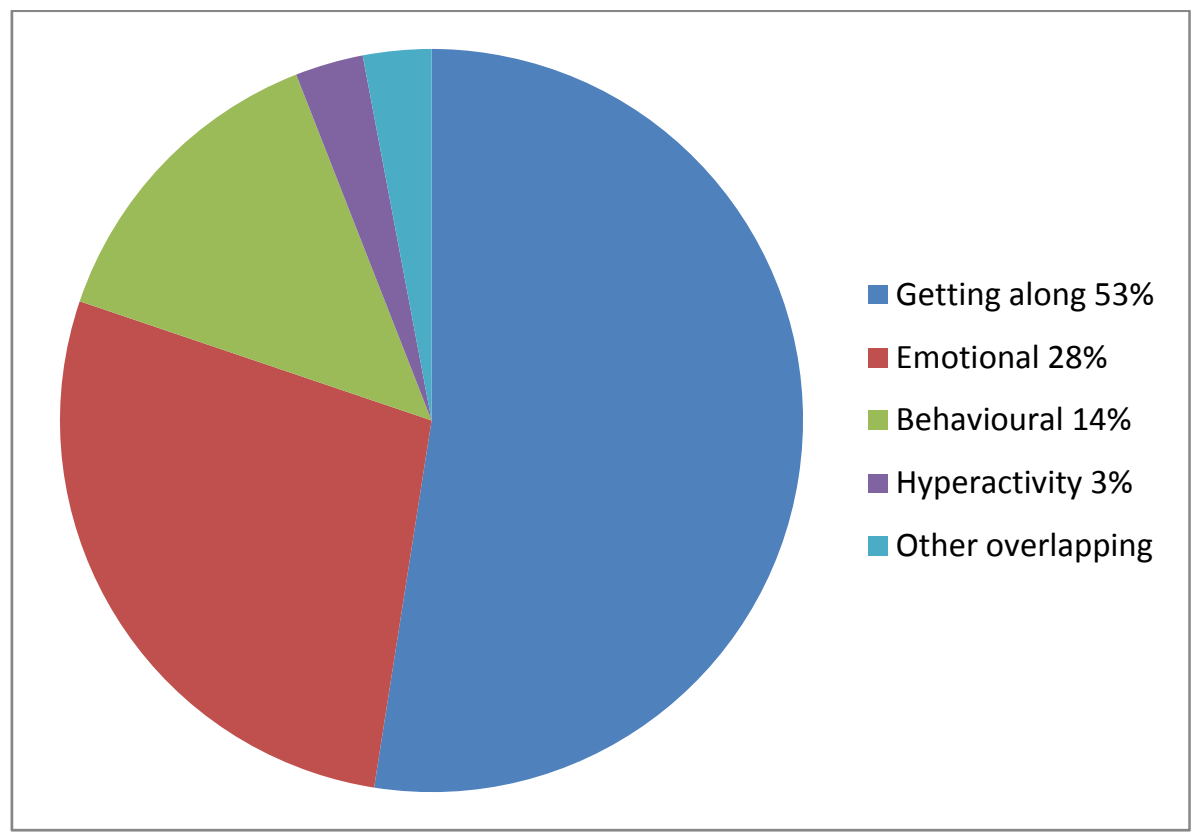

Figure 2. Categorisation of TME goals according to subscales of SDQ

\subsubsection{Analysis of Goals for Adults}

Of the 24 children where goals were set pre and post intervention, 2 of those children had goals for adults only. Overall 7 goals were set for adults; 1 for a parent, 6 for setting staff. All 7 goals showed improved TME outcomes, of between 2 and 7 progressive points.

Table 2. Scale Point Progress for Adult's TME Goals

\begin{tabular}{lcccccc}
\hline & Some progress & \multicolumn{2}{c}{ Good progress } & \multicolumn{2}{c}{ Extremely good progress } \\
\hline Amount of progress (points on 0-10 scale) & 2 & 3 & 4 & 5 & 6 & 7 \\
\hline Number of goals that progressed by this amount & 2 & 1 & 0 & 1 & 1 & 2 \\
\hline
\end{tabular}

Goals for adults linked to the SDQ strands of behaviour (57\%), peer relationship difficulties (29\%) and hyperactivity (14\%). Examples of goals for adults included:

'Staff will encourage $G$ to take part in a turn taking/shared activity with another child and adult support for three minutes every morning.'

'Practitioners will develop a positive relationship with $H$ and be sensitive and responsive to her needs, feelings and interests.' 


\subsection{SDQ Data}

\subsubsection{Overall Stress Scores}

The Overall Stress measure is based on 20 questions where a reduction in scores shows positive change i.e. those in all areas except for pro-social and gives a range of scores between 0 and 40. In Table 3 the percentages have been calculated to 1 decimal place and due to rounding this may not equal $100 \%$ exactly in all cases.

Table 3. Change in Children's Overall Stress from Staff and Parent Ratings

\begin{tabular}{lllllll}
\hline Change in Overall Stress measures & $<\mathbf{0}$ & $\mathbf{0 - 5}$ & $\mathbf{6 - 1 0}$ & $\mathbf{1 1 - 1 5}$ & $\mathbf{1 6 - 2 0}$ & $\mathbf{2 1 - 2 5}$ \\
\hline Staff & $1(4.2 \%)$ & $6(25 \%)$ & $11(45.8 \%)$ & $3(12.5 \%)$ & $2(8.4 \%)$ & $1(4.2 \%)$ \\
\hline Parents & $5(20.8 \%)$ & $9(37.5 \%)$ & $7(29.2 \%)$ & $3(12.5 \%)$ & 0 & 0 \\
\hline
\end{tabular}

Table 3 shows that there was a decrease in Overall Stress for the majority of children as rated by setting staff (96\%) and by parents (71\%). Staff noted more of a reduction in Overall Stress levels than parents.

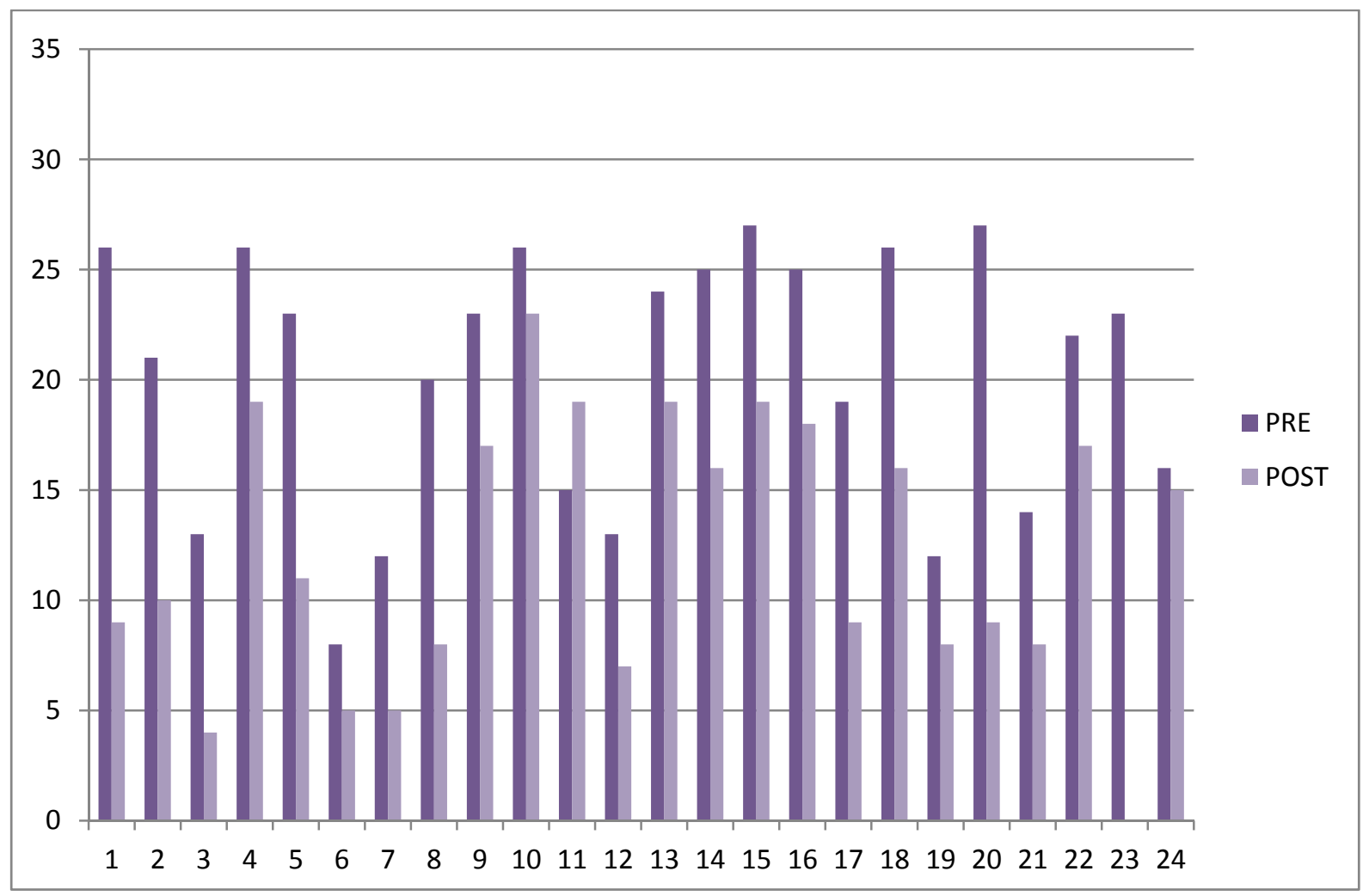

Figure 3. Staff SDQ Individual Overall Stress Pre and Post Scores 


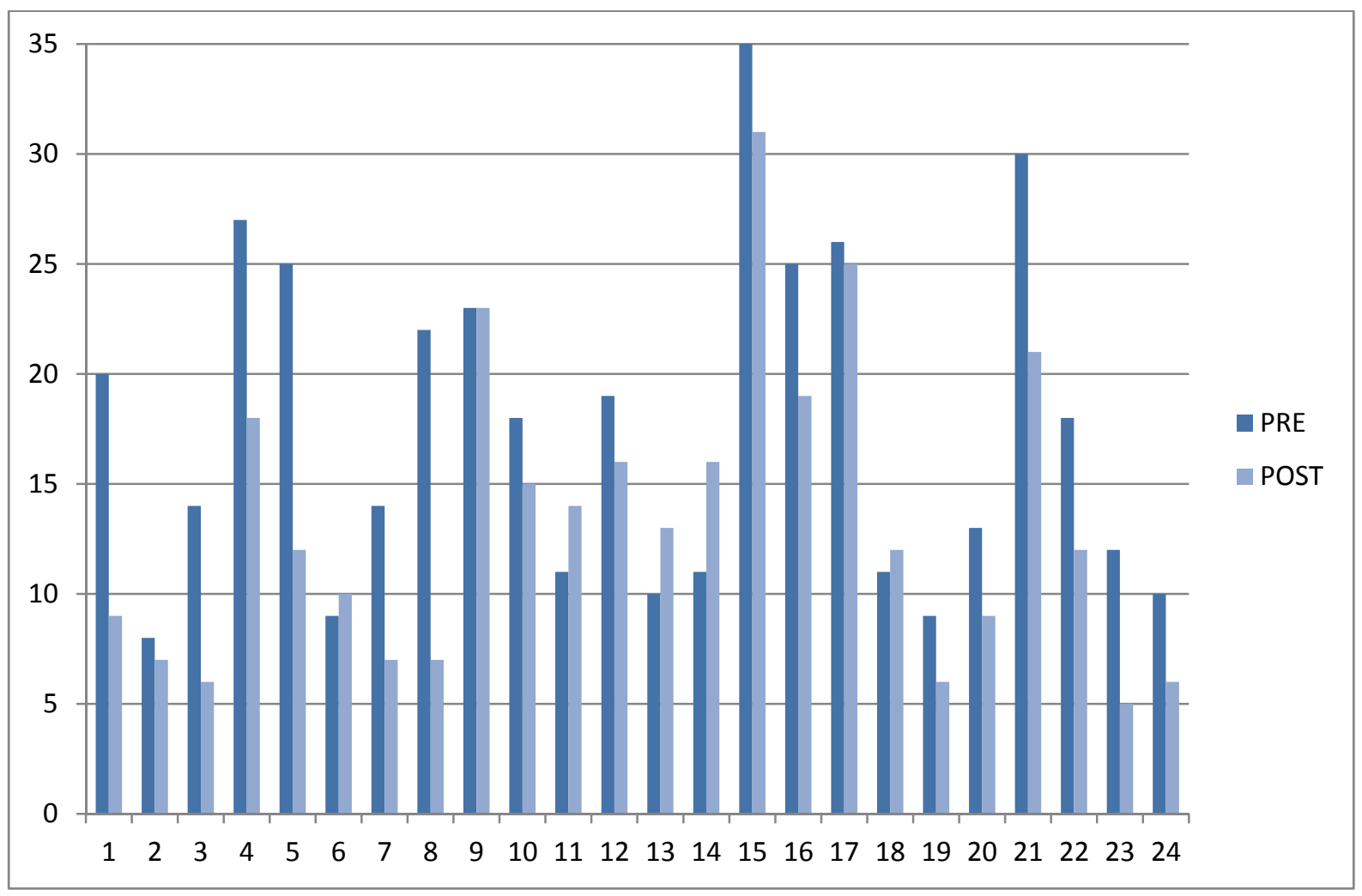

Figure 4. Parent SDQ Individual Overall Stress Pre and Post Scores

\subsubsection{Prosocial Scores}

Table 4. Change in Children's Prosocial Scores from Staff and Parent Ratings

\begin{tabular}{llllll}
\hline Change in Prosocial Behaviour measures & $<0$ & 0 & $1-3$ & $4-6$ & $7+$ \\
\hline Staff & $1(4.2 \%)$ & $2(8.4 \%)$ & $17(70.8 \%)$ & $4(16.7 \%)$ & 0 \\
\hline Parents & $5(20.8 \%)$ & $6(25 \%)$ & $9(37.5 \%)$ & $4(16.7 \%)$ & 0 \\
\hline
\end{tabular}

Table 4 shows that there was an increase in prosocial behaviour for the majority of children who received the Reflect intervention. Setting staff ratings showed more children increased their scores in prosocial behaviour ( $88 \%$ ) than parent ratings $(54 \%)$. 


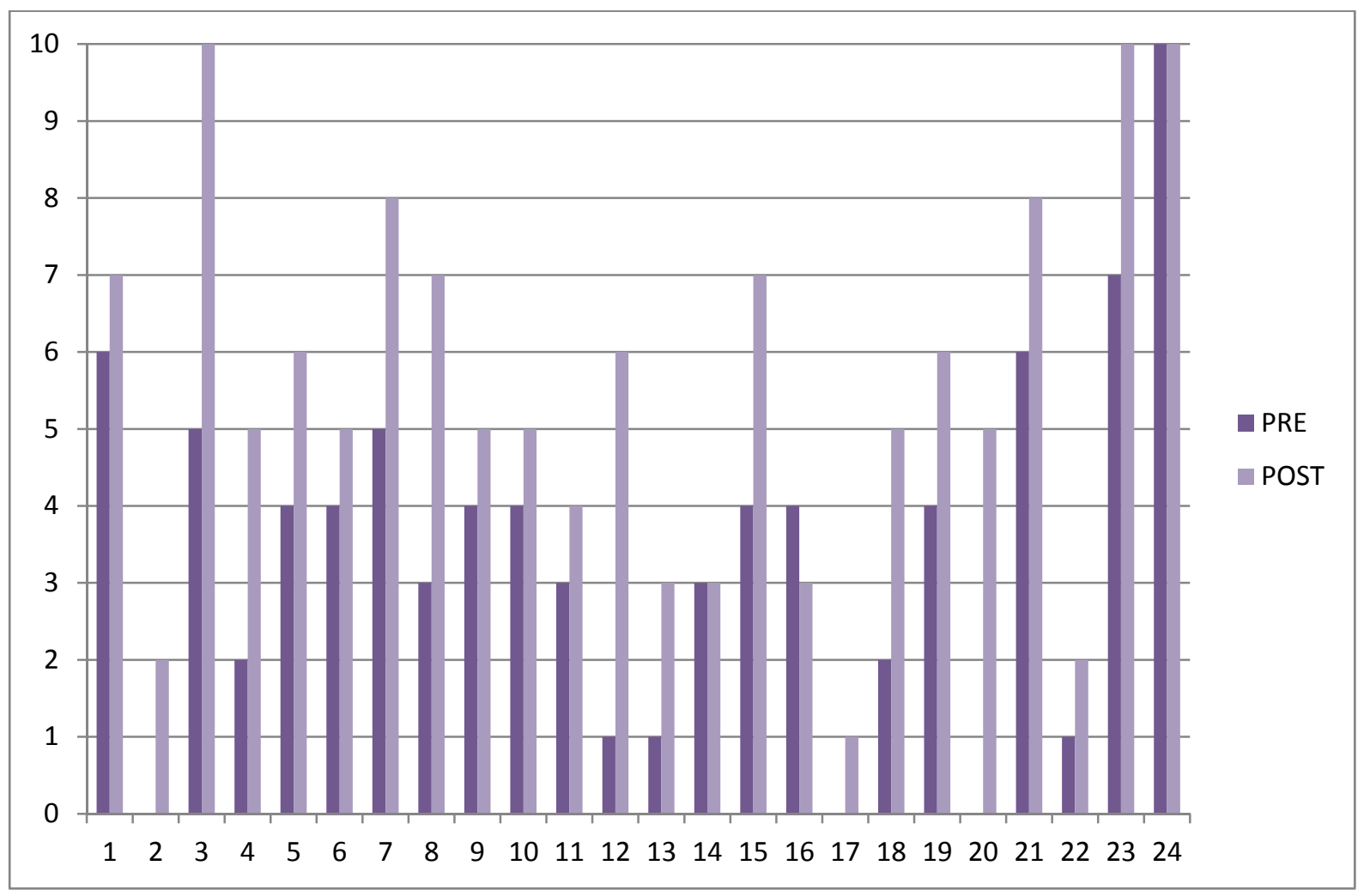

Figure 5 Staff SDQ Individual Prosocial Behaviour Pre and Post

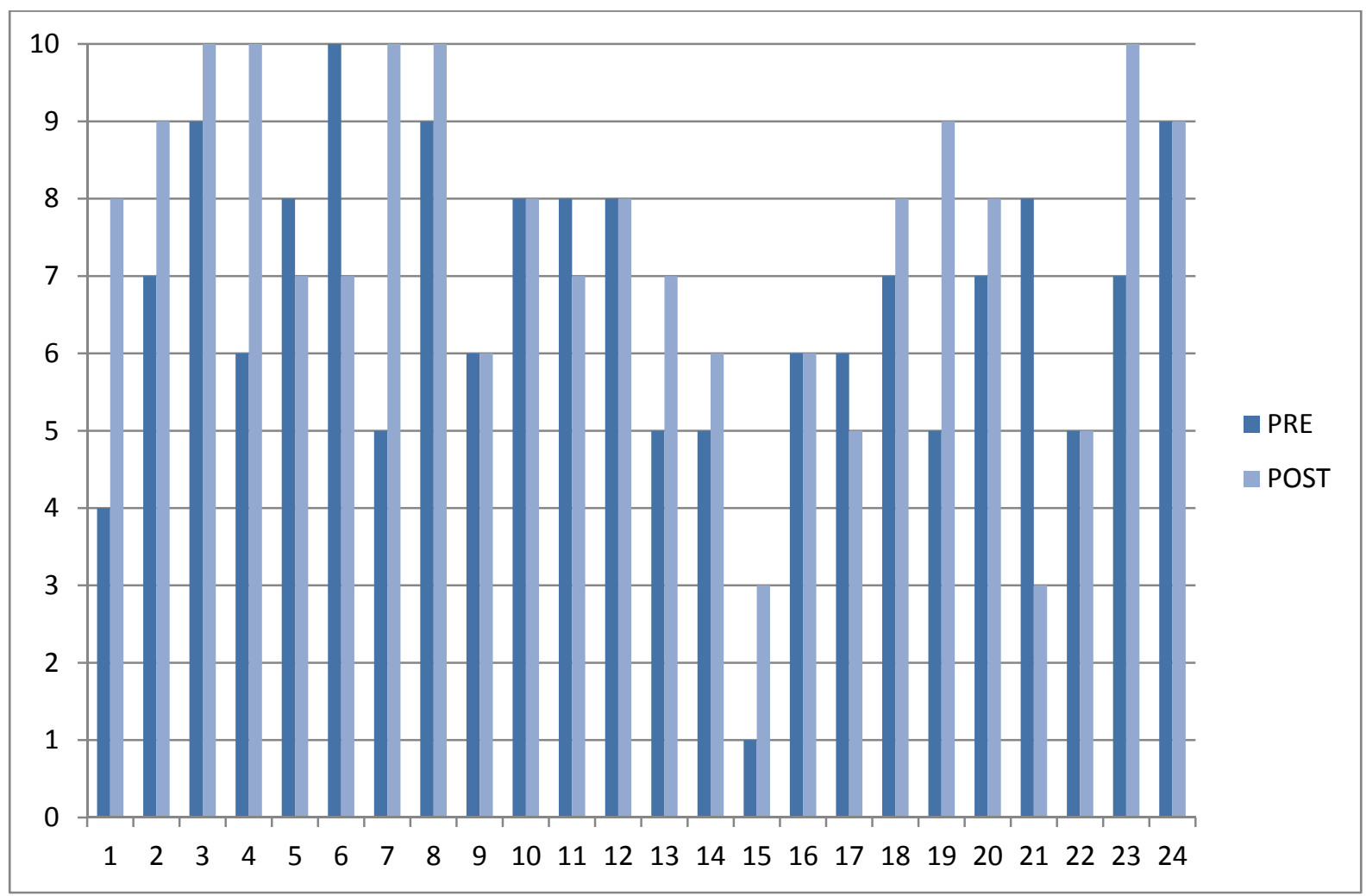

Figure 6. Parent SDQ Individual Prosocial Behaviour Pre and Post 


\subsubsection{SDQ Overall Impact}

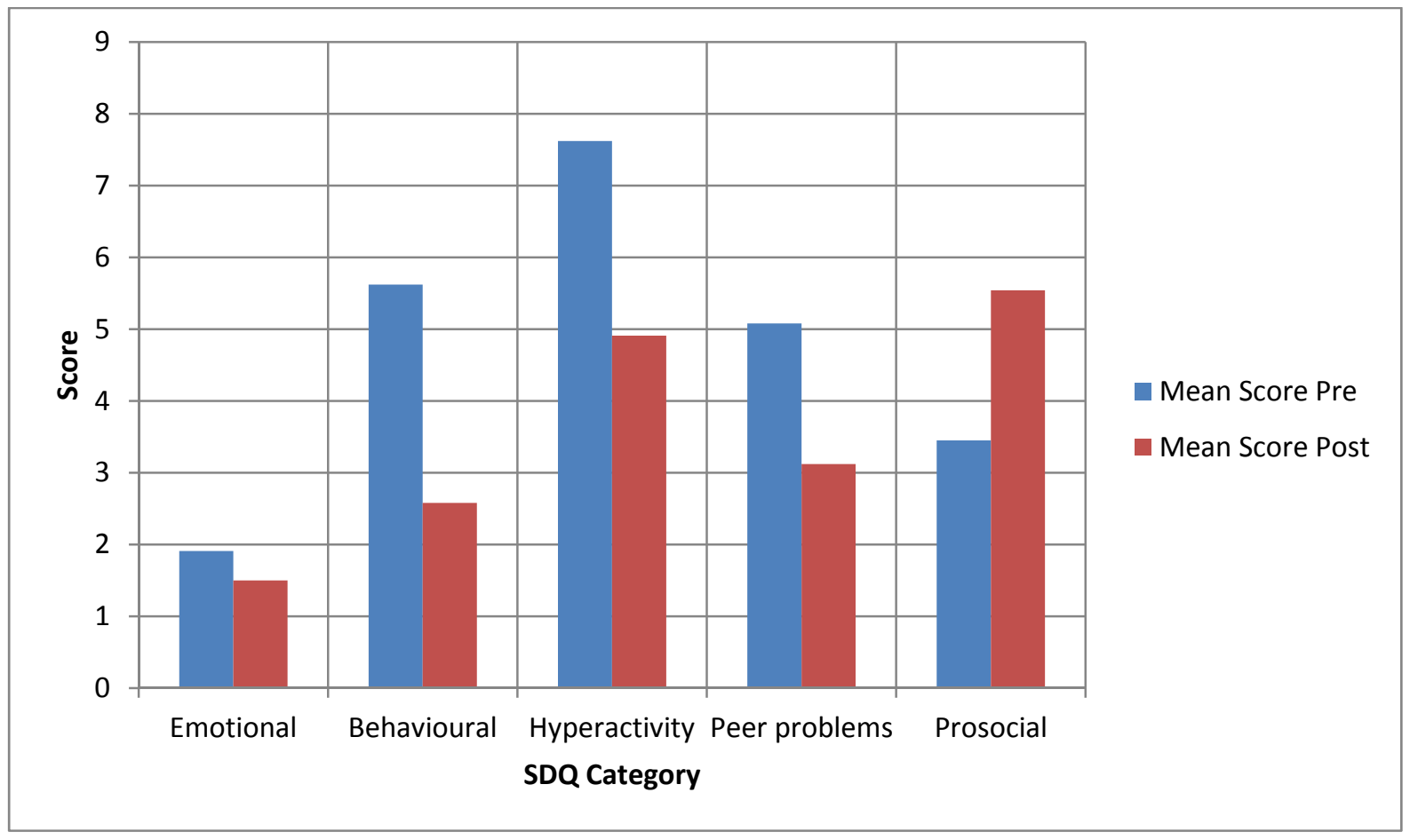

Figure 7. Mean Scores of SDQ Pre and Post data from staff responses

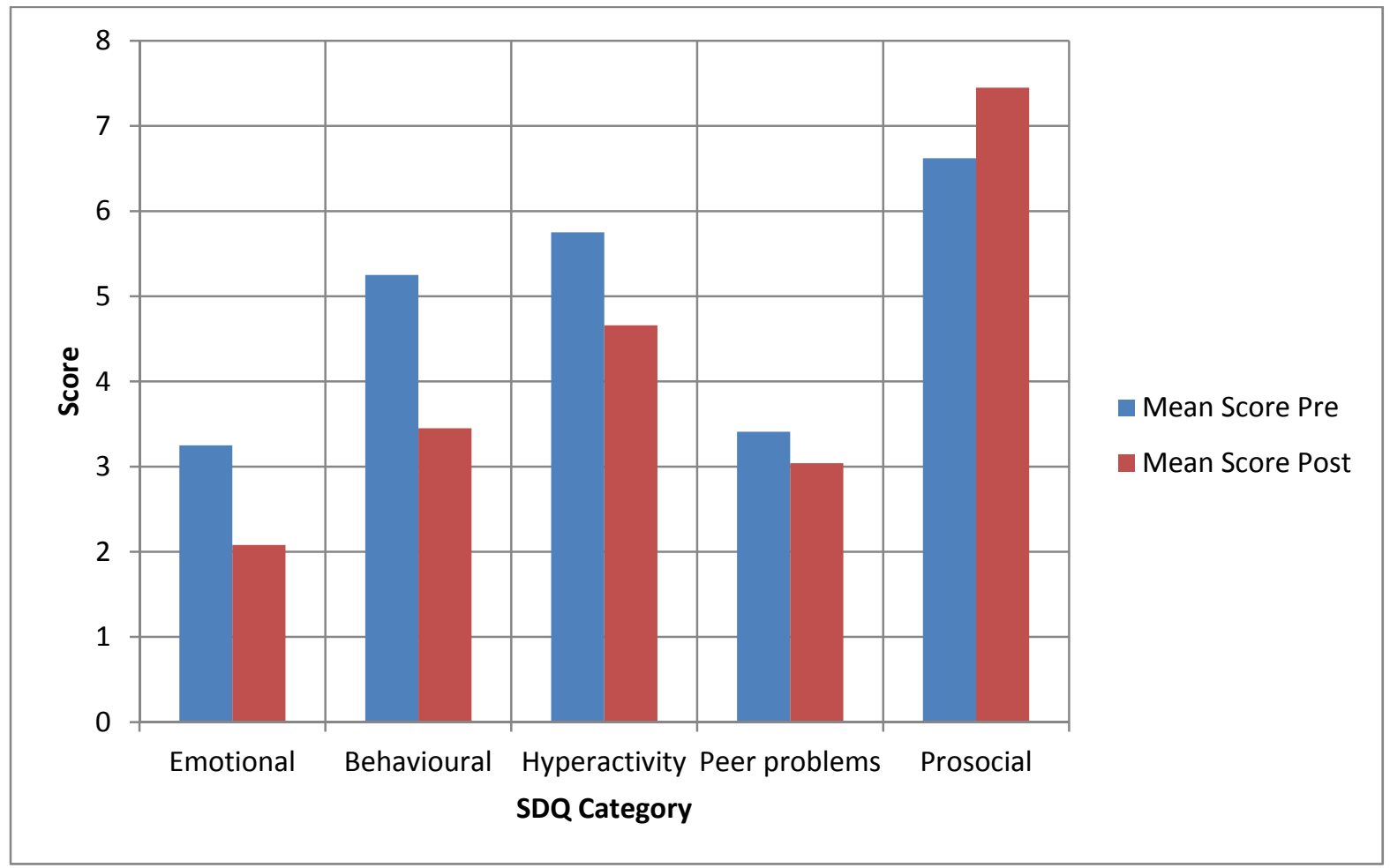

Figure 8. Mean Scores of SDQ Pre and Post data from parent responses

These results are based on average scores for the 24 children. This implies a positive trend for all 5 subscales of the SDQ. Effects for setting staff were greater. For staff ratings, mean scores in the emotional sub-scale improved the 
least ( 0.41 scale point), whilst mean scores in the behavioural sub-scale improved the most ( 3.04 scale points) followed closely by hyperactivity and inattention ( 2.71 scale points). For parent ratings mean scores in the peer problems sub-scale improved the least $(0.37$ scale point), whilst mean scores in the behavioural sub-scale improved the most (1.8 scale points).

Table 5. Statistical Analysis of Change in Mean SDQ Scores

\begin{tabular}{lllll}
\hline & \multicolumn{3}{c}{ Parent } & \multicolumn{3}{c}{ Teacher } \\
\cline { 2 - 5 } & t Stat & $\mathrm{p}$ value & $\mathrm{t}$ Stat & $\mathrm{p}$ value \\
\hline Overall stress & $* 4$ & $\mathrm{p}<0.001$ & $* 7$ & $\mathrm{p}<0.001$ \\
Emotion & $* 3$ & $\mathrm{p}=0.006$ & 1.5 & $\mathrm{p}=0.15$ \\
Behavioural & $* 5.2$ & $\mathrm{p}<0.001$ & $* 5.9$ & $\mathrm{p}<0.001$ \\
Hyperactivity & $* 2.7$ & $\mathrm{p}=0.01$ & $* 6.7$ & $\mathrm{p}<0.001$ \\
Getting along & 1.2 & $\mathrm{p}=0.26$ & $* 5.1$ & $\mathrm{p}<0.001$ \\
Kind and Helpful & -1.8 & $\mathrm{p}=0.08$ & $*-6.3$ & $\mathrm{p}<0.001$ \\
\hline
\end{tabular}

Two tailed, paired t-tests were performed on the data. Results show statistically significant mean differences in Overall Stress scores before and after the intervention, as rated by parents $(\mathrm{t}(23)=4.0 ; \mathrm{p}<0.001)$ and teachers $(\mathrm{t}(23)=7.0 ; \mathrm{p}<0.001)$. Analysis of each of the subscales are also shown with scores marked with $\mathrm{a} *$ indicating statistically significant results. The negative score for Kind and Helpful indicates positive progress. See Appendix I for a full break down of results from the t-tests.

\subsubsection{Banding of SDQ Scores}

The SDQ has been provisionally banded to produce cut off points such that around $80 \%$ of children aged 2 to 4 years would be considered close to average, $12 \%$ slightly raised, $4 \%$ high and $4 \%$ Very High (or the reverse for the pro-social scale where very low describes the band for children having greatest difficulty).

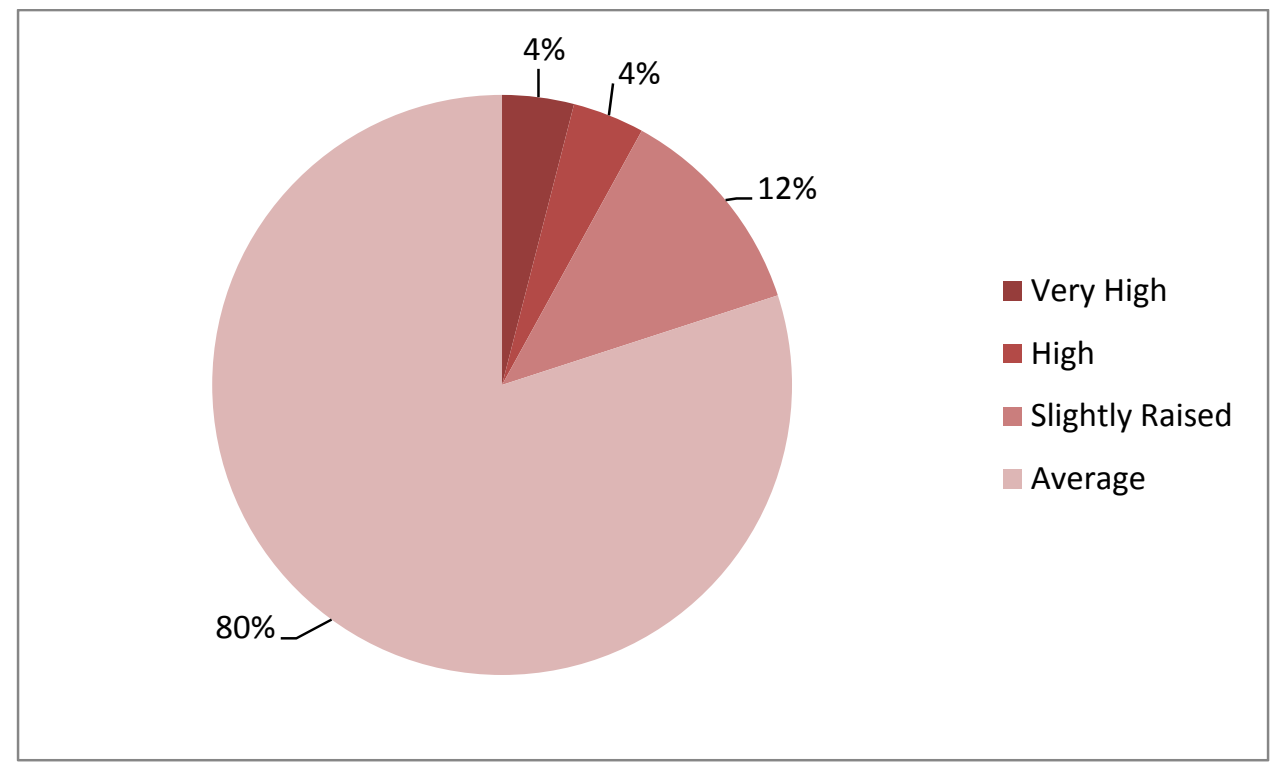

Figure 9. SDQ Banding for General Population

The children's scores in all sub-scales of the SDQ were categorised according to this banding system. Figures 10 and 11 compare the change in proportions of children whose scores fell within each of these bands pre and post intervention. For a full set of banding results for all sub-scales within the SDQ see table 8 in Appendix H. 


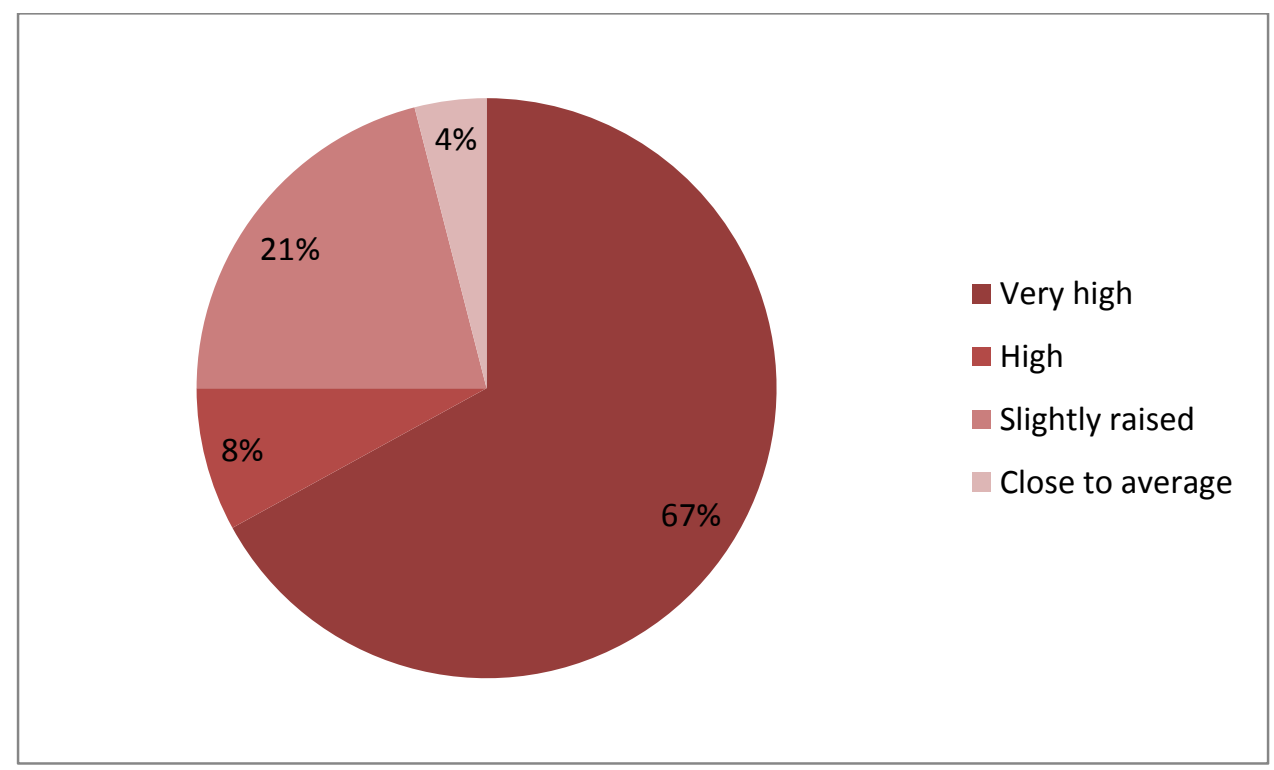

Figure 10. Pre Reflect SDQ Score Bandings from Staff Ratings

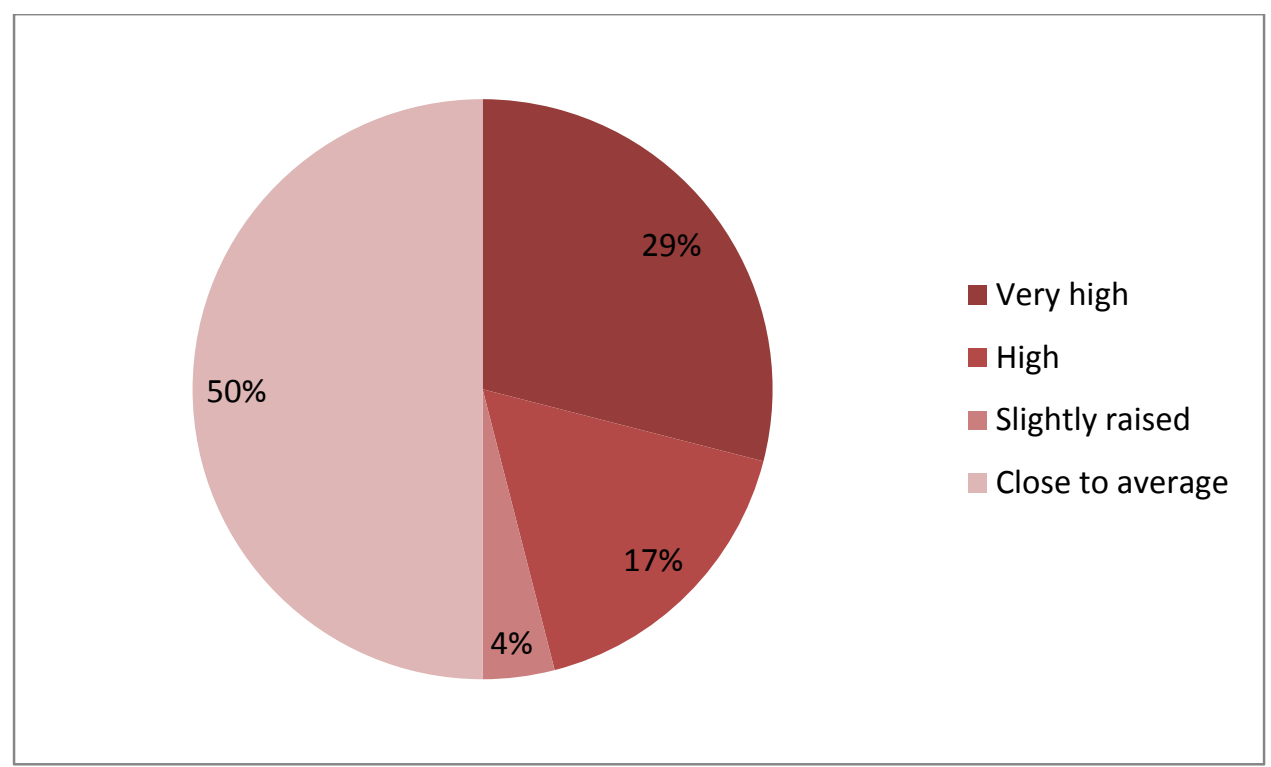

Figure 11. Post Reflect SDQ Score Bandings from Staff Ratings

This shows that $75 \%$ of children pre-intervention were classified as Very High or High on the SDQ scales according to staff ratings which reduced to $46 \%$ post intervention. Those causing most concern i.e. the Very High banding reduced by $38 \%$ post intervention. 


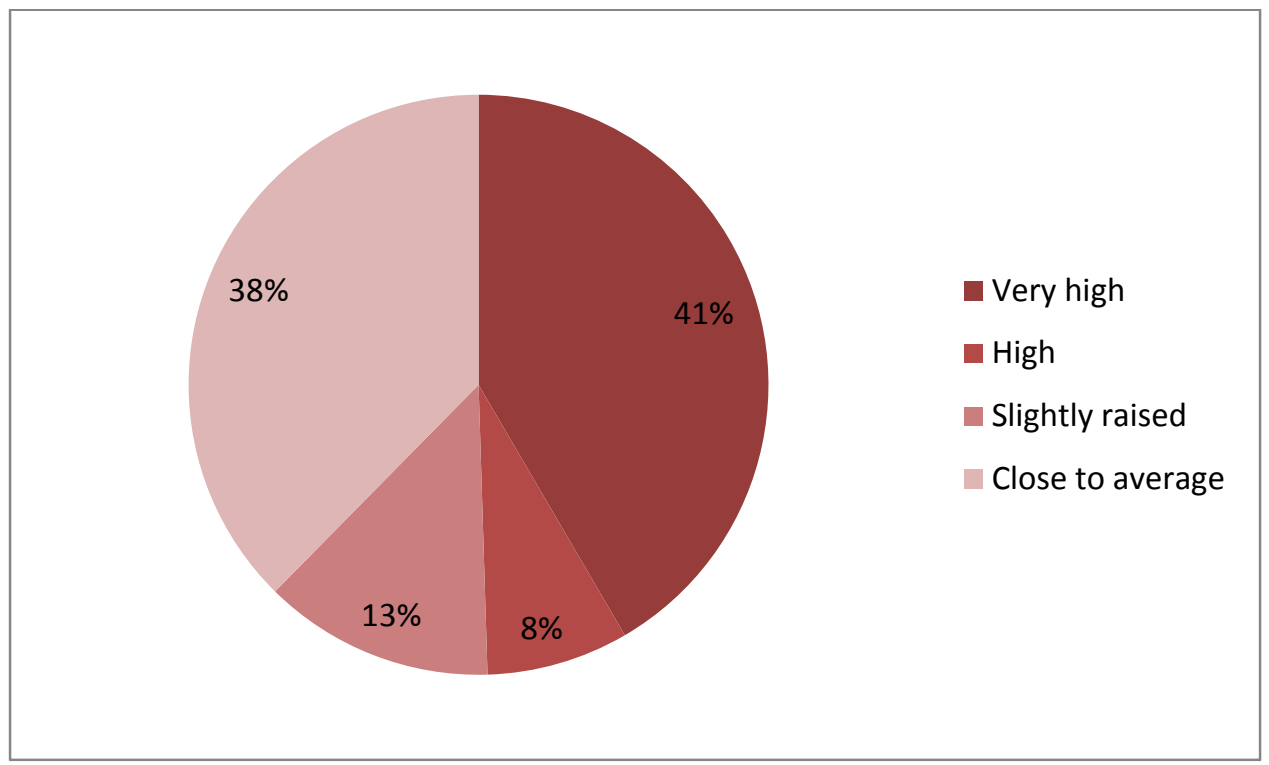

Figure 12. Pre Reflect SDQ Score Bandings from Parent Ratings

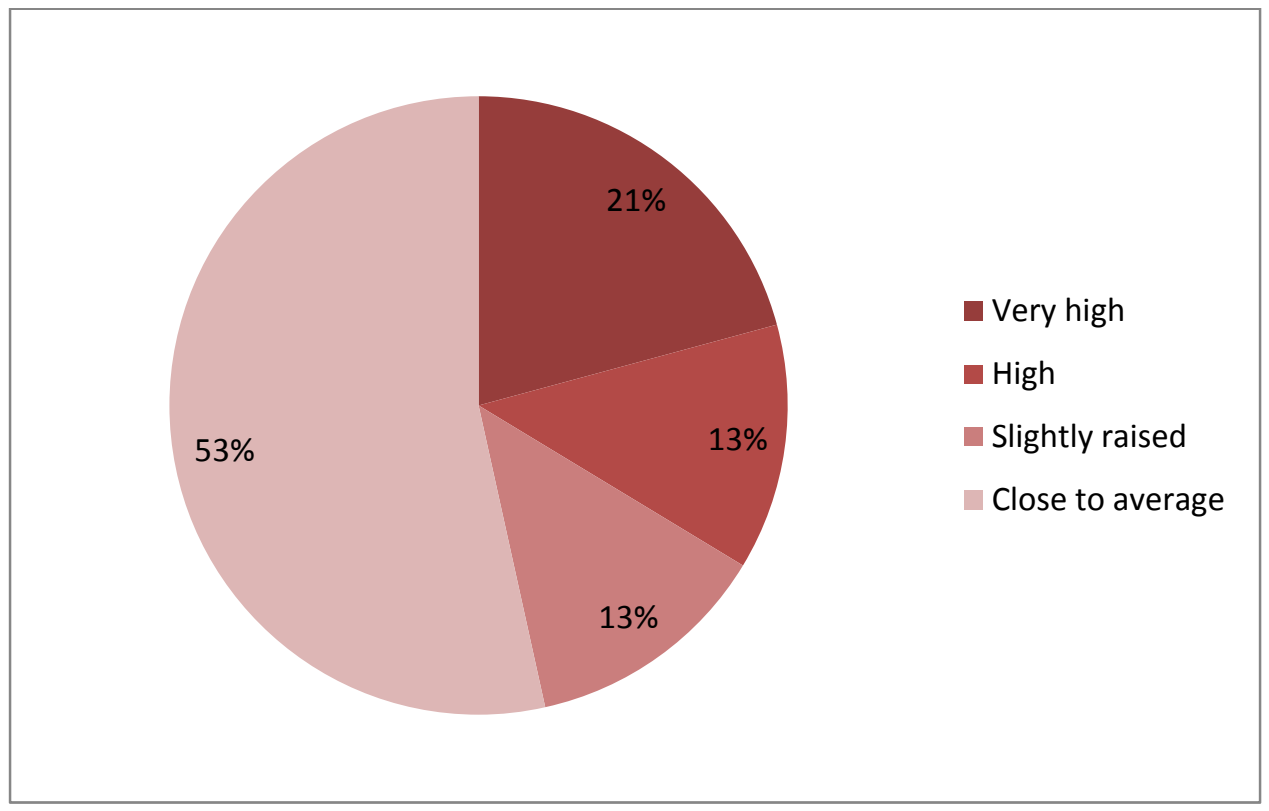

Figure 13. Post Reflect SDQ Score Bandings from Parent Ratings

This shows that $49 \%$ of children pre-intervention were classified as Very High or High on the SDQ scales according to parent ratings which reduced to $34 \%$ post intervention. Those causing most concern i.e. the Very High banding reduced by $20 \%$ post intervention.

\subsubsection{Additional Impact}

Table 6.

\begin{tabular}{lllll}
\hline & Not at all & A little & A medium amount & A great deal \\
\hline$\%$ of Parents who gave rating & 4 & 21 & 37.5 & 37.5 \\
\hline$\%$ of Staff who gave rating & 0 & 8 & 29 & 63 \\
\hline
\end{tabular}


Table 6 shows results from part of the SDQ which asks about other impact of the work that was done. Results show that $96 \%$ of parents and $100 \%$ of staff involved in the Reflect intervention reported that it had been helpful to them in other ways.

\subsection{Setting Staff/Practitioner Evaluation Data}

Of the 31 children that participated in the Reflect intervention, 23 staff evaluation questionnaires were returned (return rate of $74 \%$ ). Their responses were analysed and some broad categories emerged in response to each question on the questionnaire.

Table 7. Staff evaluation summary of responses

\begin{tabular}{|c|c|c|}
\hline Question & Categories and themes & Quotes from practitioners \\
\hline \multirow[t]{4}{*}{$\begin{array}{l}\text { 1. What have you } \\
\text { been most pleased } \\
\text { with in relation to } \\
\text { the difference seen in } \\
\text { the child, since the } \\
\text { start of this } \\
\text { intervention? }\end{array}$} & $\begin{array}{l}\text { Self-regulation: } 14 \text { out of } 23 \\
\text { staff who responded (61\%) } \\
\text { were most pleased with the } \\
\text { child's ability to calm and } \\
\text { show greater self-regulation, } \\
\text { where there were noticeably } \\
\text { less physical incidents with } \\
\text { other children during their } \\
\text { play. }\end{array}$ & $\begin{array}{l}\text { 'A seems more calm and is able to calm down after a 'crisis } \\
\text { moment' quicker' } \\
\text { B's ability to think about his actions.....he now takes into account } \\
\text { the feelings of others.' } \\
\text { 'He behaves appropriately most of the time and is self-regulating } \\
\text { more consistently.' } \\
\text { 'I have noticed the hitting has virtually stopped.' } \\
\text { 'C's behaviour has been less aggressive, including no biting.' } \\
\text { 'How quickly D is able to calm himself down.' }\end{array}$ \\
\hline & $\begin{array}{l}\text { Social interaction: } 12(52 \%) \\
\text { stated that the child was able } \\
\text { to show greater ability to share } \\
\text { and turn take, and had } \\
\text { developed more positive } \\
\text { relationships with other } \\
\text { children. }\end{array}$ & $\begin{array}{l}\text { 'Seeing E building a bond with a special friend.' } \\
\text { 'How F is interacting more with his peers.' } \\
\text { 'Has formed friendships with other children.' } \\
\text { 'G is more tolerant of other children, joining in and sharing with } \\
\text { them). }\end{array}$ \\
\hline & $\begin{array}{l}\text { Communication: } 6(26 \%) \\
\text { were most pleased with how } \\
\text { the child had developed better } \\
\text { communication skills. }\end{array}$ & $\begin{array}{l}\text { 'H is using his words more.' } \\
\text { 'His speech has improved' } \\
\text { 'I's use of words towards the other children.' } \\
\text { 'She now solves any issues using her words and not her hands.' }\end{array}$ \\
\hline & $\begin{array}{l}\text { Emotional intelligence: } 5 \\
(22 \%) \text { were most pleased with } \\
\text { how the child was able to } \\
\text { describe how they were } \\
\text { feeling and had developed } \\
\text { their emotional literacy. }\end{array}$ & $\begin{array}{l}\text { 'The way J is now able to label most emotions that he is feeling.' } \\
\text { 'Talking more about how he's feeling.' } \\
\text { 'Starting to be able to tell me if he's happy.' }\end{array}$ \\
\hline $\begin{array}{l}\text { 2. Who else has } \\
\text { noticed a difference } \\
\text { and what have } \\
\text { others said? }\end{array}$ & $\begin{array}{l}21(91 \%) \text { said that other staff } \\
\text { members/colleagues in the } \\
\text { child's setting had noticed a } \\
\text { 'difference' in the child's } \\
\text { emotional and behavioural } \\
\text { responses. Additionally, } \\
\text { parents, extended family and } \\
\text { external visitors also noticed a } \\
\text { difference. }\end{array}$ & $\begin{array}{l}\text { 'He now plays lovely.' } \\
\text { 'I can deal with K now, he is a real pleasure.' } \\
\text { 'He now has more good days than bad now.' }\end{array}$ \\
\hline $\begin{array}{l}\text { 3. What have you } \\
\text { personally found } \\
\text { most helpful? }\end{array}$ & $\begin{array}{l}\text { Structure: } 3(13 \%) \text { said that } \\
\text { the clear structure and } \\
\text { guidelines of Reflect had been } \\
\text { most helpful. }\end{array}$ & $\begin{array}{l}\text { 'Clear guidelines' } \\
\text { 'Having a structure to reflect and clear targets where to go next', }\end{array}$ \\
\hline
\end{tabular}


Strategies: $8(35 \%)$ reported that receiving guidance from the EYIW's on appropriate strategies to support the child had been most helpful.

'Being able to identify some of the early warning signs i.e. that he is feeling restless or bored with an activity and it's time for a change.'

'Remembering the 3 steps; calming, naming and stating what I want him to do.'

'The Strategies and ideas to help L manage his behaviour.'

'The strategies to use and tips on ways to avoid frustration for M.'

'Tips (EYIWs name) has given me throughout the programme.'

Supportive reflection: 10 (43\%) said the opportunity to liaise and discuss the child and receiving support from the EYIW worker and gain a different perspective was most helpful.

'A different perspective from someone coming in from outside.'

'One-to-one feedback with (EYIWs name) discussing strategies.'

'Having feedback, positive and constructive.'

'The support from EYIW. I also feel that I am much calmer whilst working with N.'

'(EYIWs name) has been a great help through this course helping me to understand how the Reflect programme will and does help children.'

'Having the opportunity to discuss (with the EYIW) the child's behaviour and personal, social and emotional behaviour.'

'The support and reassurance of (EYIWs name).'

'Having someone to talk to and support me regarding his behaviour.'

Video feedback: $6(26 \%)$ also mentioned having the opportunity to watch their practice and interaction with the child during the video feedback/playback was most helpful.

'I found looking at the videos taken helpful as we don't always get to see how we interact with the children'

'watching the playback on the video recording'

'Being able to watch the video back and reflect on my practice and interaction with the child'

'Being filmed and observed myself - seeing exactly what actions I do during an activity without realising it'

4. Do you feel you have changed your practice in any way since the Reflect programme with the EYIW began?

\section{Professional practice: 6 (26\%) mentioned changes and impact on practice at an individual level, for example, with all of them developing confidence to work directly with the focus child}

'Feeling more confident in my ability to allow him time to calm himself.'

'Now setting activities for the child's developmental age as opposed to their actual age.'

'Role playing feelings and how to deal with them.'

'Talking about children's emotions and helping them to understand why they feel the way they do.'

'Naming emotions for $\mathrm{O}$ and using mirrors to help $\mathrm{O}$ see his emotions.'

Systemic: $10(43 \%)$ reported changes and impact on the wider team/ practice
'We have a wider variety of rewards for $\mathrm{P}$ to strive towards now, which seems to be having an impact.'

'Whole staff have remembered the training.'

'We all have a positive attitude towards children with behaviour issues, giving them a cuddle and helping them to understand why they do things they do.'

'We as a setting are more tuned into Q's communication attempts.'

'We are now able to analyse observations on tapestry in greater detail and extend children's learning.'

'We are all using the same strategies for R, which has given the team more confidence.' 
'We have changed the structure of activities to meet the child's needs as well as his peers.'

'Being more aware and putting the 5 steps into everything we do.'

5 to Thrive: 13 (57\%) 'I stand back more and remind him to use his words.'

reported revisiting and 'I am looking for the trigger signs from I that I may need to step in applying principles and to support him.'

strategies from 5 to Thrive.

'I'm quite happy to sit and 'hug it out' until I feel he's ready to go and play again.'

'I'm more aware of how to use the blocks (5 principles) effectively.'

'I'm offering more cuddles when a child needs it.'

\begin{tabular}{|c|c|}
\hline $\begin{array}{l}\text { 5. What do you plan } \\
\text { to do next, which } \\
\text { may have been }\end{array}$ & $\begin{array}{l}\text { Individual: } 17 \quad(74 \%) \\
\text { suggested that they would } \\
\text { continue to apply and use the }\end{array}$ \\
\hline $\begin{array}{l}\text { triggered by the } \\
\text { EYIW's work with }\end{array}$ & $\begin{array}{l}\text { Reflect strategies with the } \\
\text { same and/or other children. }\end{array}$ \\
\hline
\end{tabular}

EYIW's work with same and/or other children. you and this child?

'Keep giving positive re-enforcements and fully support him in his play to encourage good friendships'

'To continue with strategies and ideas that have already been put into place'

'I will continue to use the Five to Thrive with all the children in our setting in the future'

'Continue everything that we have been doing to keep improving'

Group: 5 (22\%) said they 'Small group work to encourage turn taking and managing feelings' would be applying the principles as a group based intervention.

'I will continue encouraging role play with a small group of children to share and tolerate others'

Setting: 4 (17\%) said that they 'I play to support the team in Nursery to work with the child using would share this practice more what I have learnt' widely within their settings.

'Plan to go through the reflect programme with the rest of my colleagues, and also video each other so we can review and discuss'

Question
6. Do you have any
suggestions for how
the Reflect package
could be improved?

Other responses

$3(13 \%)$ suggested greater involvement with parents/carers including sharing of the video.

$2(9 \%)$ wanted more EYIW visits to the setting.

$1(4 \%)$ suggested twilight training for all setting staff.

$1(4 \%)$ wanted more explanation of the package

Other suggestions related to:

- $\quad$ use of video including

- $\quad$ accessing more video sessions

- $\quad$ viewing other practitioner videos to help develop their own ideas

- $\quad$ Parents and carers having a more active role in the videoing process.

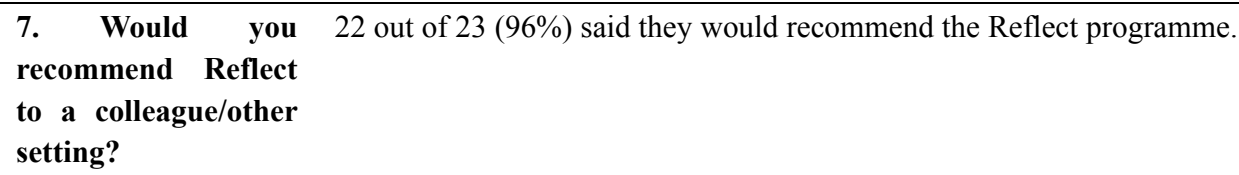

'I feel the Reflect programme is a good way for all practitioners to realise and remind themselves of what positive things we do in settings and how we interact with children also as a prompt to remind us of simple interactions and practices that are often overlooked.'

'We have gained knowledge that would also help us to use on another child.' 
'Without the help from (EYIWs name) and her positive attitude I wouldn't have been successful with this child.'

'It's lovely to see how much M has come along with allowing other children to play alongside.'

'I would like to thank (EYIWs name), she has provided fantastic support and advice to the setting during Reflect to build practitioner's confidence and improve our practice.'

'(EYIWs name) is a great support and made the 6 weeks very positive and rewarding, which really benefitted the child and the setting.'

\subsection{EYIW Evaluation Data}

The five EYIWs met to evaluate the intervention, its delivery and the impact they thought it had from their own perspective. Their responses were collated under broad headings 4.4.1 to 4.4.6

\subsubsection{Reflections about Five to Thrive}

- Most time was spent talking, looking for and unpacking 'Cuddle' and 'Relax' behaviours

- How the simplest things can make the biggest difference

\subsubsection{What EYIW Learned}

- How powerful the strengths based aspect and use of video was in supporting change

- How important it is to have the setting manager 'on board'

- That very small changes in practice, often have the biggest impact

- How intense for them as workers, this sort of intervention can be to deliver and the importance of timely casework supervision

\subsubsection{What EYIW Think Setting Staff Learned}

- That it is their own behaviour that has the biggest impact on changing the child's behaviour

- To see the whole child again, not just the behaviour

- To observe and interpret aspects of the children's behaviour more accurately, for example the sorts of behaviours measured by the emotional difficulties scale

- That some setting policies about physical touch intended to keep children and staff safe, were detrimental to well-being

\subsubsection{What EYIW Noticed the Children Learn}

- Calming techniques

- How to manage their feelings

- To accept praise and positive reinforcement

- More able to adapt and manage change

- That adults like them

\subsubsection{Data Gathering and Evaluation Tools}

Overall, the EYIW felt that SDQs, TMEs and staff evaluations were good ways to show progress and impact and worth continuing. SDQs involved parents, got practitioners to really think hard about the child and inform where the TME goal(s) should focus. They felt some of the questions were negatively worded in the SDQ but actually this often led to difficult but honest and open discussion. TMEs were used effectively, especially where everyone was involved in setting the goal. Some felt it would work better to set the TMEs after the first video session.

The EYIW felt that the EYFS data gathering needed further consideration and whilst useful as a possible long term measure, it did not add anything to the intervention. Likewise, whilst not intended as an evaluation tool, they reported unanimously that the environmental audit did not bring anything extra to the intervention and possible environmental changes were raised and discussed naturally in relation to the Five e.g. talking about a cosy book corner when discussing Relax or Cuddle. This made it more meaningful and more likely to impact on practice than looking at the audit had done. 


\subsubsection{What They Would Do More of or Different}

- Spend more time explaining what Reflect is and is not, at the planning stage and including setting managers more in that discussion

- Consider building in some linked work in the home. One setting sent copies of each of the KCA prompt sheets home as they were given to the setting. In this case the involvement of the parent in this way and in SDQ, TME setting and review meetings was very positive and the parent reported that it had 'Changed her life' and her understanding of her child

- Include a follow up visit or future contact to keep momentum going

- Offer a mini training / support to disseminate practice for other staff in the setting

- Drop the audit

- Reduce time taken for gathering / entering data to have more time for working in settings.

- Possibly increase time in between setting visits in some instances

\section{Discussion and Limitations of Research}

\subsection{TME Goals}

The TME goals set related most often to getting along with others, based on setting staff and parent perceptions. Setting staff have therefore prioritised the need to work on peer relationships and the impact that the child's behaviour has on other children in the setting. From staff perceptions, relationships with others appeared more important than some other areas and may have influenced their choice of goal. This may be highlighting the greatest difficulty that the child's behaviour was causing for them within the setting, with their aim being to reduce conflict and increase positive interactions with peers rather than thinking about the specific skills that the child needed to develop or the interpersonal aspect of the intervention. Perhaps at the start of the intervention they did not realise that this was about changing their behaviour to make the child feel more secure and promote self-regulation through increased opportunity for co-regulation. Most TME goals focused on getting along, however this is not the area that showed most significant impact in SDQ results (see below).

TME results show that all staff noticed observable differences and possibly a change in perception of how they viewed the child post intervention. This could be in part that they felt closer to and more positive about the child, having connected with them through the intervention. Some of the children did not show progress in areas of the SDQ but all of the children showed progress towards the set goals. Perhaps this also illustrates a more positive view of the child with greater understanding and a different interpretation of behaviours post intervention, even where some behaviours deteriorated according to the SDQ.

\section{$5.2 S D Q$ Scores}

The effects shown by SDQ measures were generally reported as greater by setting staff than parents for Overall Stress and pro-social behaviours. This seems likely to be a result of the intervention having been delivered in the setting and being aimed at supporting change for practitioners and their interactions with the child. As an intervention had not directly happened for the parent, other than engagement and knock on effects of being part of the pre and post intervention target setting and discussions about the child, this would be expected. This could be linked to setting staff feeling more empowered, more connected and more empathetic towards the child. Also practitioners may be in a better position to notice and report that children's relationships with peers had improved, as parents may not observe this in the home and may not see their child as much with other children outside of the home setting. Neither categories of Getting Along or Being Kind and Helpful showed statistically significant positive changes from the parental ratings. The results may also be implications of how the child is feeling which is impacting on Overall Stress i.e. the child is being responded to by more attuned and receptive setting staff, they in turn respond more positively with and around those adults in particular (reciprocity).

Results indicate that post intervention, most children were more caring and kind to others and more aware of others' feelings within the settings. Staff ratings showed that $88 \%$ of children's scores on the Prosocial scale increased and the mean score change for them was 2.09 , which is approximately a $20 \%$ improvement in these skills and a statistically significant result.

Although the sample size is relatively small in this study for SDQ analysis, mean scores were calculated to show general trends of impact across the 5 different categories and statistically significant positive change for 4 of those 5 for staff ratings. This shows favourable impact of the intervention and gives strong evidence to suggest the intervention should be continued. Again the impact scores were generally greater for staff than parents. The 
behaviour sub-scale showed the greatest improvement with the emotional sub-scale scores showing least improvement for staff ratings (which was the category which did not show a statistically significant result). In some instances individual children showed no change or an apparent deterioration from scores on the emotional difficulties measure, especially noticeable for staff. This could be explained by a changing shift in how the children were expressing themselves; moving from acting out aggressively towards others when upset (reduced behaviour difficulties), to showing this in more emotional ways such as crying. Perhaps these children are on their journey towards being able to recognise and label their emotions, as some did show from progress against related TME goals. Other emotional scale questions include items such as child shows more signs of worry or is more clingy or nervous. Perhaps this demonstrates a journey through more self-awareness and feeling closer to staff as they reach out to them when they feel scared rather than (pre-intervention) acting out when they experience these feelings. Another interpretation based on the EYIWs views are that behaviours were interpreted and assigned more accurately as emotional responses post intervention, as they were thinking more about the child's feelings. The reasons underlying behaviours, not just the behavioural outbursts may have been given greater consideration.

The results from the analysis of bandings within the SDQ demonstrate that on the whole the intervention was targeted at the right children i.e. those most in need. Although comparisons with the general population should be read with caution for such a small scale study, these changes on SDQ banding post intervention show favourable results in particular movement from bands of most concern (Very High and High) towards the average. There were some (2) children whose scores for Overall Stress increased post intervention (possibly due to factors unconnected to the intervention) and so the children in the Very High and High band pre and post intervention were not the same children in all cases, i.e. most moved down to lower bands and a few moved up.

\subsection{Staff Evaluations}

Setting staff frequently referred to and noticed children's increased ability to self-regulate. Perhaps this was a result of them being more available for opportunities to co-regulate with them. The disproportionate time spent focusing on Cuddle and Relax (from Five to Thrive) reported by the EYIWs may be an illustration of the biggest challenge for setting staff in bridging the gap between expert (the person who delivered the information to them on the training) and reality (them trying to implement what they had heard and learnt back in their setting). These were perhaps the elements that practitioners found most difficult to translate into their direct work with the children and which challenged some of their views, feelings and initial emotional response to the challenging behaviours that they were seeing. When a child kicked or bit them pre-intervention, their first response within a behaviour management construct may not have been to be calm or provide comfort. By guiding and showing them examples of where this worked, they may have changed their constructs and become more nurturing towards the child and really understood how to help the child learn to self-regulate. Thus more opportunities for co-regulation resulted. Also some issues related to 'no touch' or safe touch setting policies were explored in discussions between the EYIWs and setting staff.

Many of the categories that emerged in the setting staff evaluations reiterate the TME and SDQ data sets and relate to improved behaviour, social interaction and general emotional literacy of the children. Again their reflections indicate that staff found the intervention to be valuable and helpful in addressing children's SEMH difficulties.

The reflections of EYIWs and setting practitioners indicate a change in hearts and minds of the setting staff. The intervention seemed to help to reframe how a child is perceived and therefore received by the adults around them. When an adult is more attuned and on a child's side, this nurturing approach increases empathy and viewing the world from the child's perspective. It helps the child to stop the 'fight' or 'flight' response in stressful situations and so be more present for learning.

It is interesting to note that time spent liaising with the EYIWs was well received and regarded as supporting the success of the programme and also the staff's efficacy in delivering the programme. This may be indicative of the benefits and need for supervision and support for those working most closely with children in challenging situations. A need for increased casework supervision for the EYIWs mirrored this.

\subsection{Limitations of This Research}

Although the results are encouraging and show progress against many SDQ scores and all of the TME goals, it should be acknowledged that these results are based on a relatively small sample size of just 24 full sets of data for the children. Therefore it cannot be taken for granted that the results would transfer to a larger population. The staff evaluations were also a small sample size of 23 . However this does represent a good return rate of $74 \%$ and setting staff seemed keen to share their learning and appreciation of the intervention through these evaluations and subsequently when a number of them shared examples of this work at a conference through case study 
presentations.

The use of TME goals is another potential limitation as this a subjective measure, with the staff involved commenting on the progress of the children in their care. They could have over-scored as to score low may have been seen as failure on their part to change and improve their practice. They could have over-scored as they had become closer to and more supportive of the child, seeing them in a better light that at the start of the intervention. However on the whole, many of the children were at high risk of exclusion when Reflect was started and the EYIWs who were able to see things more objectively were part of that TME review progress and had seen evidence through the video footage and observations of the changes that had occurred. A potential video coding activity of the $1^{\text {st }}$ and last videos could be considered to add validity to the change data for example coding the children's behaviour for signs linked to areas of the SDQ or the adults behaviour for empathy based comments or mental state comments which could be used to indicate greater connectedness and better relationships with the children. This would add qualitative change data for the setting staff's development and learning.

The pre and post measures taken compared progress over the period of the intervention. There was no longitudinal measure of sustained progress or transfer of behavioural improvement between settings such as when the children started at school. Although anecdotal evidence of post transition progress being sustained has since been received, this was not available at the time of the data analysis or included in the study.

\section{Conclusion}

The Reflect intervention has been an empowering and helpful resource for pre-school practitioners working with some of their most challenging children. Even where absolute change and a total solution for the child's emerging SEMH needs was not found, the increased empathy and connectedness all staff involved (setting staff and EYIWs) have experienced, helped the children to be better included. The hypothesis that this adds to resilience and promotes school readiness is as yet unproved and this would be an interesting next step to explore.

From video analysis and observations, the EYIW found that the principles and 5 building blocks of Five to Thrive were not fully implemented or translated into settings after staff had attended the initial training. Evidence, especially the qualitative data from the staff involved shows that Reflect supported this embedding of new knowledge, which was one of the aims of this specific intervention design.

As more children will be attending settings for up to 30 hours a week following changes to current UK government funding for working families, a practitioner's potential influence on a child's development is also due to increase and so this is a timely intervention. Staff who participated in Reflect developed the skills needed to become secondary attachment figures and develop the key worker role for this challenging group of children. Practitioners with these skills of emotional warmth, availability and empathy will be invaluable as children spend more time in settings.

The positive impact on prosocial behaviour is encouraging and could have a future role in reducing bullying. "More than 14 percent of UK children said they are bullied 'frequently'. The EPI [The Education Policy Institute who carried out the research] says this figure is significantly above the OECD [Organisation for Economic Co-operation and Development] average of 8.9 per cent, and the fourth highest of all 34 countries surveyed."(Morton 2017) Although this was not considered or intended at the start of the intervention it is another useful potential area to build on.

Based on this preliminary study and despite the small sample size, it would seem that Reflect is worth continuing and investing in further, with the refinements and learning from the evaluation being applied.

\subsection{Next Steps}

\subsubsection{Proposed Adaptations to the Intervention}

- Consider a parallel intervention with parent/ carer(s) in the home alongside Reflect e.g. Five to Thrive Parenting Programme as used in the Barnado's project (Pettit 2015), Video Interaction Guidance, Incredible years or Triple P in liaison with Early Help services - perhaps this could be offered at the time Reflect is requested? The EYIW completing the parental pre-intervention SDQ in the home prior to the TME goal setting meeting would give an opportunity to give out the Five to Thrive parent booklet and discuss a referral for Early Help. If not accepted, this could be revisited again at the review stage

- Consider a targeted pro-social or social skills intervention for setting staff to deliver to the children through small group work with peers, as these skills start to emerge during Reflect

- Consider how children who may be experiencing SEMH difficulties but who do not act out and show this through challenging behaviour, can better access Reflect. Very few of these withdrawn children have been 
included so far. In Cornwall all children in the care of the local authority for 3 months undergo psychological assessment leading to a recovery plan. Implementing Reflect could be an action from that plan

- Consider other ways of identifying children who might benefit from Reflect such as raising awareness of ACE descriptors and associated vulnerabilities for children with setting staff

- Regarding the timing of the TME goal setting, perhaps identification of a goal for the setting staff would be best placed to happen after the first video. Subsequent small steps towards that goal could be set and reviewed in visits 2 to 4 . Goals for the child seem to be well placed at the initial meeting with as many of the adults most involved with the child present. This fosters collaboration, consultation and joint sign up for change as well as opportunities to celebrate success when the goals are reviewed

- Elements of the intervention will be reviewed and refined, in order to reduce administration time, data gathering and focus on the most helpful elements of the intervention. Initially, the SDQ will be collated and scored within a child's electronic records, the audit will no longer be used, the EYFS scores will no longer be gathered specifically and entered manually, the reporting of TMEs and general records will be refined in order to be more useful in support of transition to school

- Consider including a tool or reflection opportunity to capture the child's voice and experience of Reflect and relationships within the setting

- Arrange a focus group of parents and setting staff that have experienced Reflect themselves to consider; the intervention, proposed family support and the processes involved. Consider further adaptations in light of their feedback

\subsubsection{Changes to Other Areas of Professional Practice}

- Adults who participated in Reflect frequently cited a desire to do more, look at more video in the programme, look at other people's videos and reach out to more staff in their setting. To address this and build on the success of Reflect for the child, a whole setting VERP programme is being developed for delivery in settings where they have engaged and seen benefits from Reflect. This should now be rolled out and evaluated, with a link back to Five to Thrive as part of the analysis

- Additional group casework supervision will be available to the EYIW and the Signs of Safety model of supervision encouraged for individual supervision

- Consideration will be given as to whether there could be benefits of rolling this intervention out to other children, for example those in their reception year at school. A single case-study to explore this has been trialled. A pilot study of 4 or 5 further cases could show impact, in liaison with the Educational Psychologist for the school

- In many cases development of children's ability to name and describe their feelings was identified as an outcome. Could other workers such as those within Early Help services be given training on Emotion Coaching to help families support continued development of this in the home?

- Consider discussions with health colleagues about Reflect as part of a pathway to more specialised CAMHS support, where children who do not respond to this intervention may go on to access provision at a higher tier. At least consider referral to CAMHS as a possible next step at the end of the intervention where progress has not been evident and discuss with health colleagues in advance that this is likely, so that these pre-school referrals are given a raised profile on receipt of referral

\subsubsection{Further Research and Data Collection}

- Given the apparent increase in emotional behaviours observed with the hypothesis that this is a logical part of the children's emotional development (i.e. from acting out to feeling and naming concerns and fears), it would be interesting to measure those emotional behaviours specifically again to look for patterns of change as the children's expression of emotion continues to develop. Building in a 6 month post intervention SDQ repeat would be beneficial. If not this, consider further exploration of the apparent change from reduced behavioural to increased emotional difficulties

- Consider including a further measure for school readiness ratings for this cohort e.g. Gumpel (2003) or the Speed DIAL-4 (Mardell \& Goldenberg, 2011)

- Gather evidence on the child's voice to explore if the suggested finding that the change in quality of relationship and feelings of security, are what is driving the improvements in behaviour

- Consider parents view in more detail 
- Contrast these results with future cohort who receive Reflect in their pre-school setting and parental input through Early Help services alongside

- Consider more in depth qualitative research with setting practitioners who have participated to explore the hypothesis that their view of the child is a factor in the improved behaviour. What is the interaction between feelings of connectedness to the child - seeing the child more positively - child feeling more 'loved' and accepted and so relaxing and behaving in a calmer and more socialised way as they feel better held

- Collect a snap shot of EYFS data from the setting at the start for possible future analysis. A transition project looking at this and considering re-collecting EYFS data at the end of the children's reception year could follow. The focus could be on how far from expected levels the children are, rather than comparing pre and post measures due to the difficulties experienced in collecting and comparing this across settings

- Another potential line of enquiry which links to the development of emotional literacy is the accurate use of language of emotion around children by parents and practitioners

- A control group e.g. another group of children experiencing difficulty but not included, or a parallel group of same aged peers could be measured at the same time as the target child at the same points in time at the same setting. This could give more validity to the change results. Other possible control groups could be considered e.g. families referred for early help where ACEs are present but where Reflect did not take place

- Continue to gather data until Reflect has been delivered to a minimum of 100 children. Collate and analyse this further data and consider approaching the Education Endowment Fund (EEF) to explore further roll out, sustainability and further development of the intervention

\section{Acknowledgements}

Early Years Inclusion Workers; Tracey Hayton, Gill Holt, Michelle Kevern, Kelly Martin and Karen Richardson who delivered the intervention and Senior Locality SENCO; Judith Bayley from the Early Years Inclusion Service which is a department within Cornwall's Educational Psychology Service

Kate Cairns Associates who developed and produced Five to Thrive

\section{References}

Ainsworth, M.S., \& Bowlby, J. (1991). An Ethological Approach to Personality Development. American Psychologist, 46, 333-341. https://doi.org/10.1037/0003-066X.46.4.333

Bakermans-Kranenburg, M. J., van IJzendoorn, M. H., \& Juffer, F. (2003). Less is More: Meta-analyses of Sensitivity and Attachment Interventions in Early Childhood. Psychological Bulletin, 129(2), 195-215. https://doi.org/10.1037/0033-2909.129.2.195

Bandura, A. (1986) Social foundations of thought and action: A social cognitive theory. Englewood Cliffs, NJ: Prentice Hall.

Barlow, J. (2014).Professor for Public Health in the Early Years University of Warwick. Why VIG? Conference paper presentation at 6th Video Interaction Guidance (VIG) international conference.

Bowlby, J. (1969). Attachment and loss: Vol. 1. New York: Basic Books

Cairns, K. (2002). Attachment, trauma and resilience: Therapeutic caring for children. Coram BAAF publishing

Canterbury Christ Church University. (2016). Reflections on emotional health, wellbeing and character in education.

Cozolino, L. (2006). The neuroscience of human relationships. London, W.W.Norton and Co.

Davies, S. (2013). A Cross-Party Manifesto The 1001 critical days The importance of the conception to age two period http://www.1001 criticaldays.co.uk/

Department for Education. (2014). Special educational needs and disability code of practice: 0 to 25 years. Statutory guidance for organisations which work with and support children and young people who have specialeducational needs or disabilities. Ref: DFE-00205-2013

Department for Education. (2015). Special Educational Needs and Disability Code of Practice: 0 to 25 years. Retrieved from https://www.gov.uk/government/publications/send-code-of-practice-0-to-25

Department of Health (2015). The impact of adverse experiences in the home on the health of children and young people, and inequalities in prevalence and effects. http://cdn.basw.co.uk/upload/basw_13257-1.pdf

De Shazer, S. (1985). Clues, investigating solutions in brief therapy. W.W.Norton and Company 
Dunsmuir, S., Brown, E., Iyadurai, S. \& Monsen J. (2009) Evidence-based Practice and Evaluation: from Insight to Impact. Educational Psychology in Practice, 25 (1). https://doi.org/10.1080/02667360802697605

Durlak, J., Weissberg, R., Dymnicki, A., Taylor, R., \& Schellinger, K. (2011). The Impact of Enhancing Students' Social and Emotional Learning: A Meta-Analysis of School-Based Universal Interventions. Child Development, 82(1), 405-432. https://doi.org/10.1111/j.1467-8624.2010.01564.x

Felitti, V., Anda, R., Nordenberg, D., Williamson, D., Spitz, A., Edwards, V., Koss, M., \& Marks, J. (1998). Relationship of Childhood Abuse Household Dysfunction to Many of the Leading Causes of Death in Adults. The Adverse Childhood Experiences (ACE) Study. American Journal Preventive Medicine, 14(4), 245-258. https://doi.org/10.1016/S0749-3797(98)00017-8

Fredrickson, B. L. (2001). The Role of Positive Emotions in Positive Psychology: The Broaden-and-build Theory of Positive Emotions. The American Psychologist, 56(3), 218-226. https://doi.org/10.1037/0003-066X.56.3.218

Fredrickson. B., \& Branigan, C. (2005) Positive Emotions Broaden the Scope of Attention and Thought-action Repertoires. Cognition \& emotion. 19(3), 313-332. https://doi.org/10.1080/02699930441000238

Goleman, D. (2004). Emotional intelligence why it can matter more than IQ. London: Bloomsbury.

Goodman, R. (1997). Strengths and Difficulties Questionnaire (SDQ). Retrieved from www.sdqinfo.com

Gumpel, T. (2003). The use of item response theory to develop a measure of first-grade readiness. In Skouteris, H., Watson, B. Lum, J. (2012) Preschool Children's Transition to Formal Schooling: The Importance of Collaboration Between Teachers, Parents and Children. Australasian Journal of Early Childhood, 37(4,) $78-85$

Heckman, J. (2006) Skill Formation and the Economics of Investing in Disadvantaged Children. Science, 312, 1900-1902. https://doi.org/10.1126/science.1128898

Heckman, J. (2010). A Research Agenda for Understanding the Dynamics of Skill Formation. SSRN Electronic Journal. https://doi.org/10.2139/ssrn.1889178

Herndon, K. J., Bailey, C. S., Shewark, E., Denham, S. A., \& Bassett, H. H. (2013). Preschoolers' Emotion Expression and Regulation: Relations with School Adjustment. The Journal of Genetic Psychology, 174(0), 642663. https://doi.org/10.1080/00221325.2012.759525

Kate Cairns Associates. (2012). Five to Thrive: A resource for settings to improve the emotional health and well being of staff, children and families. kca publications

Kennedy, H., Ball, K., \& Barlow, J. (2017). How does video interaction guidance contribute to infant and parental mental health and well-being? Clinical Child Psychology and Psychiatry. https://doi.org/10.1177/1359104517704026

Kennedy, H., Landor, M., \& Todd, L. (2011). Video interaction guidance: a relationship-based intervention to promote attunement, empathy and wellbeing. London: Jessica Kingsley

Kennedy, H. Landor, M., \& Todd, L. (2015). Video Enhanced Reflective Practice. Professional development through attuned Interactions. Jessica Kingsley Publishers.

Kolb, A., \& Kolb, D. (2007). Experiential Learning Theory. A Dynamic Holistic Approach to Management Learning. Education and Development Department of Organizational Behaviour, Weatherhead school of Management. https://weatherhead.case.edu/departments/organizational-behavior/WP-07-02.pdf

Laevers, F. (2005). Well-being and involvement in care settings: A process orientated self-evaluation instrument for care settings. Kind and Gezin https://www.kindengezin.be/img/sics-ziko-manual.pdf

Mardell, C., \& Goldenberg, D. (2011). Speed Dial 4; Developmental Indicators for the Assessment of Learning (4th ed.). Pearson.

Martin, C. (2001). The Life Coaching Handbook. Crown House Publishing.

Masten, A., Best, K. \& Garmezy, N. (1990). Resilience and Development: Contributions from the Study of Children who Overcome Adversity. Development and Psychopathology, 2(4), 425-444 https://doi.org/10.1017/S0954579400005812

Masten, A. S., \& Gewirtz, A. H. (2006). Vulnerability and resilience in early child development. In: K. McCartney, $\&$ D. A. Phillips, eds. Handbook of early childhood development (pp. 22-43). Malden, Mass: Blackwell 
Publishing. https://doi.org/10.1002/9780470757703.ch2

Masten, A. S., \& Cicchetti, D. (2010). Editorial: Developmental Cascades. Development and Psychopathology, 22, 491-495. https://doi.org/10.1017/S0954579410000222

McGee, C., Hughes, K., Quigg, Z., Bellis, M., Larkin, W., \& Lowey, H. (2015). A scoping study of the implementation of the routine enquiry about childhood adversity. Centre for Public Health (CPH) Liverpool John Moores University.

Morton. (2017). Nurseries can play a role in improving children's well being 19 April 2017 by Katy Morton in Nursery world online. Retrieved from https://www.nurseryworld.co.uk/nurseryworld/nursery/ 1160926/nurseries-can-paly-a-role-in-improving-childrens-wellbeing

Moss, W. (2016). Bounce Back. How to be a Resilient Kid. Magination press.

Newman, T. (2004). What works in building resilience Barnado's Policy Research Unit.

Paterson, C., Tyler, C., \& Lexmond, J. (2011). Character and Resilience Manifesto The all-party parliamentary group on Social Mobility.

Perry, B. D., \& Szalavitz, M. (2006). The boy who was raised as a dog: and other stories from a child psychiatrists notebook: what traumatized children can teach us about loss, love, and healing. New York: Basic Books.

Pettitt, B. (2015). Bringing Five to Thrive Alive. Two approaches to implementing Five to Thrive with Barnado's. Barnado's Evaluation and Impact Team

Reading, R. (2013). Recognition, intervention, and management of antisocial behaviour and conduct disorders in children and young people: summary of NICE-SCIE guidance. Child: Care, Health and Development, 39(4), 615-616. https://doi.org/10.1111/cch.12074_5

Schore, A. (2001). Effects of a Secure Attachment Relationship on Right Brain Development, Affect Regulation, and Infant Mental Health. Infant Mental Health Journal, 22(1-2), 7-66. https://doi.org/10.1002/1097-0355(200101/04)22:1<7::AID-IMHJ2>3.0.CO;2-N

Shai, D., \& Belsky, J. (2011). When Words Just Won't Do: Introducing Parental Embodied Mentalizing. Child Development Perspectives, 5(3), 173-180. https://doi.org/10.1111/j.1750-8606.2011.00181.x

Siegel, D. J., \& Bryson. P. (2012). The Whole-Brain Child. Constable and Robinson Publications.

Stephens , Z., Lee, J., \& Wilde, E. (2007). Positive Behaviour Management Coaching in Schools Theory, Practice and Reflection Vol. 3, Pastoral Intervention Series. E. McNamara, Ed.

Thomas, W., \& Smith, A. (2004). Coaching solutions. Bloomsbury Publishing University of Minnesota, USA October 2013, Resilience in Development: The Importance of Early Childhood Rev. ed. encyclopedia on child development.

Whalley, P., \& Williams, P. (2015). Evaluation of Video Interaction Guidance (VIG) What works in building parenting skills and confidence to help tackle neglect. NSPCC Evaluation Department.

Wilshaw, M. (2016). Unknown children - destined for disadvantage? Ofsted July 2016 No. 160044.

Wilshaw, M. (2016). Ofsted Annual report 2015 /16. State of the nation into the quality of schools, early years and the further education sector, including supporting statistics. Ofsted National Audit Office December 2016.

www.kca.training

www.videointeractionguidance.net 
Appendices

Appendix A

\section{Strengths and Difficulties Questionnaire}

For each item, please mark the box for Not True, Somewhat True or Certainly True. It would help us if you answered all items as best you can even if you are not absolutely certain or the item seems daft! Please give your answers on the basis of the child's behaviour over the last six months or this school year.

Child's Name

Male/Female

Date of Birth

\begin{tabular}{|c|c|c|c|}
\hline & $\begin{array}{l}\text { Not } \\
\text { True }\end{array}$ & $\begin{array}{c}\text { Somewhat } \\
\text { True }\end{array}$ & $\begin{array}{c}\text { Certainly } \\
\text { True }\end{array}$ \\
\hline Considerate of other people's feelings & & $\square$ & \\
\hline Restless, overactive, cannot stay still for long & & L & \\
\hline Often complains of headaches, stomach-aches or sickness & & 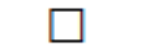 & \\
\hline Shares readily with other children (treats, toys, pencils etc.) & & 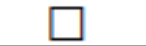 & \\
\hline Often has temper tantrums or hot tenpers & & $\square$ & \\
\hline Rather solitary, tends to play alone & & 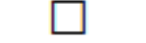 & \\
\hline Generally obedient, usually does what adults request & & $\square$ & \\
\hline Many worries, often seems worried & $\square$ & $\square$ & \\
\hline Helpful if someone is burt, upset or feeling ill & & $\square$ & \\
\hline Constantly fidgeting or squirming & & $\square$ & \\
\hline Has at least one good friend & & ए & \\
\hline Often fights with other children or bullies them & & $\square$ & \\
\hline Often unhappy, down-hearted or tearful & & & \\
\hline Generally liked by other children & & & \\
\hline Easily distracted, concentration wanders & & $\square$ & \\
\hline Nervous or clingy in new situations, easily loses confidence & & & \\
\hline Kind to younger children & & & \\
\hline Often argumentative with adults & & L & \\
\hline Picked on or bullied by other children & & & \\
\hline Often volumteers to help others (parents, teachers, other children) & & & \\
\hline Can stop and think things out before acting & & L & L \\
\hline Can be spiteful to others & & & \\
\hline Gets on better with adults than with other children & $\square$ & $\square$ & $\square$ \\
\hline Many fears, easily scared & 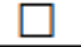 & $\square$ & ] \\
\hline Sees tasks through to the end, good attention span & $\square$ & $\square$ & $\square$ \\
\hline
\end{tabular}

Do you have any other comments or concerns?

Please turn over - there are a few more questions on the other side 


\section{Appendix B}

Goal - 1

Goal set for Child

Date goal set

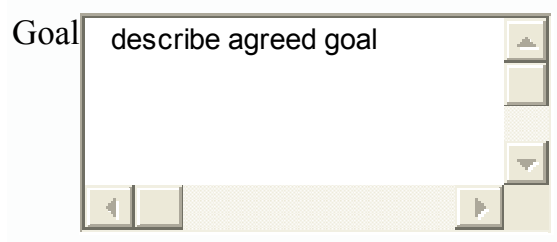

Where are you?

2

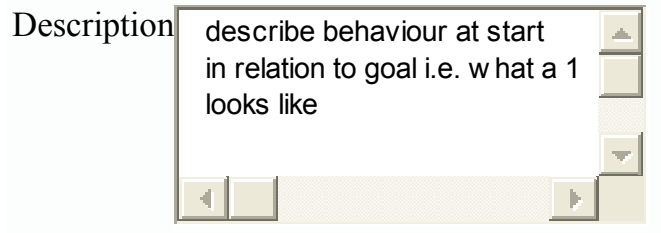

Where did you expect to get to? (What w ould have been good enough?)
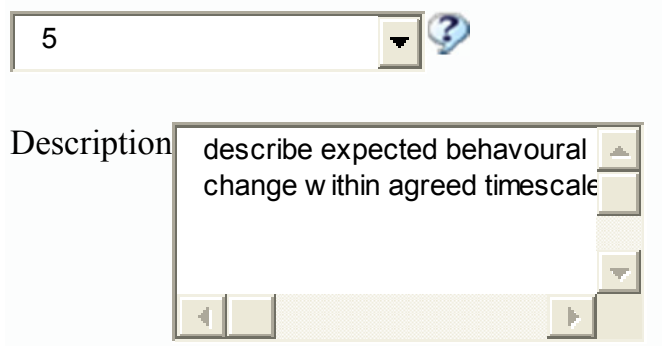

What did you get to? (Level achieved) 5

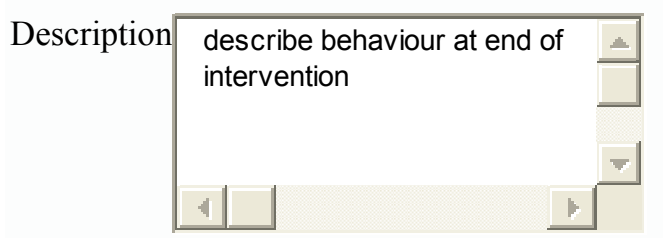

Difference 4

Date completed 


\section{Appendix C - Observation template example}

Individual Child Observation Sheet Initial Date of Birth...

Session 1

\begin{tabular}{|c|c|c|c|c|c|}
\hline $\begin{array}{l}\text { Observation } \\
\text { Date }\end{array}$ & Time & \multicolumn{4}{|c|}{$\begin{array}{l}\text { Environment } \\
\text { Who, where and what? }\end{array}$} \\
\hline \multicolumn{6}{|c|}{ TME from Senior Locality SENCO: } \\
\hline $\begin{array}{l}\text { Joint } \\
\text { observations } \\
\text { of first video: }\end{array}$ & Relax & Cuddle & Respond & Play & Talk \\
\hline \multicolumn{6}{|l|}{ Adult: } \\
\hline \multicolumn{6}{|l|}{ Child: } \\
\hline $\begin{array}{l}\text { Next Steps: (c) } \\
\text { What can you }\end{array}$ & & $\begin{array}{l}\text { o/audit) } \\
\text { u are doing? }\end{array}$ & & & \\
\hline
\end{tabular}

\section{Session 2}

\begin{tabular}{|l|l|l|}
\hline $\begin{array}{l}\text { Observation } \\
\text { Date }\end{array}$ & Time & $\begin{array}{l}\text { Environment } \\
\text { Who, what, where? }\end{array}$ \\
\hline & & \\
\hline
\end{tabular}

What have you done differently/more of since the last visit?

What has been the impact?

Observations/additional information

Next Steps: 


\section{Appendix D}

\section{Reflect Setting Evaluation}

Setting Staff Evaluation - to be completed with the practitioner most involved at the end of the intervention following the final review.

\begin{tabular}{|l|l|}
\hline Practitioner Name; & Preschool/setting; \\
\hline Initial of child; & Date of intervention start to finish; \\
& \\
\hline
\end{tabular}

1. What have you been most pleased with in relation to the difference seen in the child, since the start of this intervention?

2. Who else has noticed a difference and what have others said?

3. What have you personally found most helpful?

4. Do you feel you have changed your practice in any way since the 5 to thrive programme with the Early Years Inclusion Worker began?

If yes, how?

1.

2.

3.

5. What do you plan to do next which may have been triggered by the EYIW's work with you and this child?

6. Do you have any suggestions for how the 5 to Thrive package could be improved?

7. Would you recommend this to a colleague/other setting?

8. Any other comments?

Thank you for taking the time to complete this. Please copy this sheet for your own records prior to returning to Early Years Inclusion Worker at the end of the intervention or; 


\section{Appendix E}

\section{Early Years Inclusion Service}

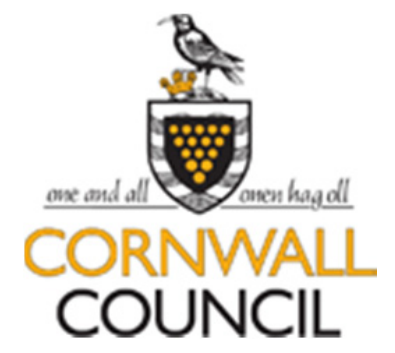

\section{Reflect - a five to thrive Intervention}

\section{Audit Sheets}

Name of Setting

Date of initial visit.

\section{Area}

Enabling Environments
The basic arrangement of the room consists of 4 to 6 areas, allowing
children to choose an activity and play in an area. Areas are easily
accessible for all children.

- The room is relaxed and a pleasant atmosphere is created

- Activities are linked to children's interests and needs

- Consideration given to the layout of the areas e.g. quiet area is away from messy play area

- Equipment and resources are at child's level for easy access

- The use of visual support strategies are in place e.g. pictures/symbols are used to label key areas and resources, choice boards, now and next boards.

- The plan of the day is made accessible to the children by using a visual timetable

- Key transitions are supported using visual strategies i.e. traffic lights/spot timers - waiting time is kept to a minimum.

- Outdoor play is available with varied learning opportunities and used in an optimal way

Rules and boundaries are explained to the children, taking their level of comprehension into account. If possible, rules and boundaries are set together with the children.

Rules are implemented consistently and children follow them with little guidance and encourage their peers also. E.g. coats on for outdoor play, 2 children at the computer.

Appropriate number of resources and materials available

E.g. It is sometimes more interesting for the children to play in a kitchen with just a few pots, instead of having to choose from a box stuffed with kitchen material. Overfilled book corners can reduce interest. One paint 
brush will cause disputes.

- A wide range of activities and materials are available

- Materials and furniture are maintained in good condition. E.g. books are not torn apart, games and puzzles are complete, doll's clothes are clean.

- A balance is maintained of adult and child led activities that supports all areas of learning

- Consideration is given to the planning of children's various needs, interests and developmental levels. E.g. there are enough toys that appeal to both boys and girls. There is enough material for the different stages.

- Transitions are well planned and supported

- Making the most of spontaneous planning E.g. if its start to snow then your plans can change.

\section{Positive Relationships}

The enthusiasm of the adult (facial expression, eye contact, intonation, etc.) and the way in which activities are offered are appealing. It enhances children's curiosity and motivates them to continue exploring.

- The adults ask questions, commentate or intervene, stimulating the children to reflect on things, to discover things, to communicate, etc.

- Adults take advantage of particular situations i.e. nappy time, snack time to pay individual attention to the children.

- The adult regularly expresses into words what the child experiences.

- Adults acknowledge and respect children's choices and support the voice of the child. E.g. an incomplete picture maybe complete to the child, a bus may have 7 wheels.

- Adults encourage independence and self-help skills.

- Activities and materials are offered in which children learn to distinguish feelings, to recognise emotions in themselves and in others and to communicate about them. E.g. Adults reassure children that it is okay to feel angry or frightened. Feelings are expressed into words by means of stories or using puppets, emotions fans/cards

- Staff are well deployed and engaged with the children where needed.

- Key person system considers compatibility of children and adult relationships

- Adults give consideration to social grouping. 


\section{Appendix F - Support Sheet}

\section{Reflect a five to thrive Intervention}

Five to Thrive Support Sheet-Relax

Relax

A child's brain will continue to grow when you relax with them.

When we are stressed our bodies are full of chemicals that make us active so we can deal with whatever is upsetting us. These chemicals can be bad for the brain if we can't get the stress under control. For a child to calm down the adult needs to remain calm.

\section{Points to remember}

- Try to end exciting play sessions with a wind down time.

- Think about relaxing spaces for children in your setting.

- Remember to look after yourself in order for you to remain calm.

\begin{tabular}{|l|}
\hline \multicolumn{1}{|c|}{ Activities to support Child } \\
\hline Hand or foot massage \\
\hline Sing or hum \\
\hline Calming lullabies \\
\hline The hugging game, with soft toys \\
\hline Relaxing in a den-use cardboard boxes \\
\hline Circle time games \\
\hline \\
\hline
\end{tabular}

\section{Adults could}

Use Fun Fit books and Little Baby Books from Birth to Three Matters for further ideas.

Provide blankets to use with children

Create a calming area in the setting

Attend regular supervision

Have regular breaks

Support colleagues

With reference to Kate Cairns Associates.

www.katecairns.com

(a) Cornwall Council

Version 01/16 


\section{Appendix G}

Example extract from observation sheet p6, to be included in transition plans

Early Years Inclusion Service

Summary from Reflect, 5 to thrive intervention

Name of child:

Early years setting:

\section{Date of intervention:}

\section{What have you done differently/more of during the Reflect intervention?}

- Increased the use of Traffic Lights to support X during transitions, all staff using Traffic Lights when X is moving from/to activities. Staff using the same language when using the Traffic Lights - Starting, Nearly Finished and Finished.

- Moving X onto other activities as he would tend to stay playing with cars in particular for a majority of the session.

- Supporting X during small group work to encourage his interaction with his peers. Encouraging him to turn take with both the use of the Traffic Lights and modelling language. Supporting $X$ with communicating with his peers to request (item/play) and bridge the language barrier of when other children/adults don't understand his first language.

Additional information:

During week 5 of the process X's Keyworker's additional support was no longer in place. J (Keyworker) was in the room supporting $\mathrm{X}$ on the sessions that the EYIW was supporting with the Reflect intervention, apart from these sessions $\mathrm{J}$ was working in the Toddler room and preschool room staff would support/carry out recommendations for $\mathrm{X}$ within the 1:8 ratio.

\section{What has been the impact?}

- $\mathrm{X}$ has built relationships with his peers, finding it easier to communicate and at times would be able to play without an adult's need to support.

- $\quad \mathrm{X}$ has at times initiated play with his peers and continue/extended the play alongside peers.

- More compliant with following routine/rules.

- Reduction in behaviour incidents.

- Going into the bigger playground area, $\mathrm{X}$ is now able to follow the rule of holding adults/child hand without running off.

- Mum and Dad have noticed that X appears more calm and relaxed.

- Pleased to be going to nursery.

Attendees at Review: 


\section{Appendix H - SDQ Data Bandings Pre and Post Reflect and Mean Scores}

\begin{tabular}{|c|c|c|c|c|c|c|c|c|c|}
\hline \multirow{2}{*}{ SDQ Area } & \multirow{2}{*}{ Sample } & \multicolumn{2}{|c|}{ Very High } & \multicolumn{2}{|l|}{ High } & \multicolumn{2}{|c|}{ Slightly Raised } & \multicolumn{2}{|c|}{ Close to average } \\
\hline & & Pre & Post & Pre & Post & Pre & Post & Pre & Post \\
\hline \multirow{2}{*}{$\begin{array}{l}\text { Emotional } \\
\text { Difficulties }\end{array}$} & Teacher & $8 \%$ & $0 \%$ & $8 \%$ & $17 \%$ & $21 \%$ & $13 \%$ & $62 \%$ & $71 \%$ \\
\hline & Parent & $33 \%$ & $11 \%$ & $13 \%$ & $8 \%$ & $4 \%$ & $8 \%$ & $54 \%$ & $63 \%$ \\
\hline \multirow{2}{*}{$\begin{array}{l}\text { Behavioural } \\
\text { Difficulties }\end{array}$} & Teacher & $67 \%$ & $21 \%$ & $8 \%$ & $17 \%$ & $4 \%$ & $13 \%$ & $21 \%$ & $50 \%$ \\
\hline & Parent & $42 \%$ & $29 \%$ & $25 \%$ & $13 \%$ & $8 \%$ & $13 \%$ & $25 \%$ & $58 \%$ \\
\hline \multirow{2}{*}{ Hyperactivity } & Teacher & $63 \%$ & $25 \%$ & $8 \%$ & $8 \%$ & $13 \%$ & $21 \%$ & $17 \%$ & $46 \%$ \\
\hline & Parent & $29 \%$ & $17 \%$ & $13 \%$ & $13 \%$ & $4 \%$ & $13 \%$ & $54 \%$ & $58 \%$ \\
\hline \multirow{2}{*}{ Getting Along } & Teacher & $42 \%$ & $4 \%$ & $21 \%$ & $29 \%$ & $25 \%$ & $33 \%$ & $13 \%$ & $33 \%$ \\
\hline & Parent & $33 \%$ & $25 \%$ & $4 \%$ & $17 \%$ & $25 \%$ & $13 \%$ & $38 \%$ & $46 \%$ \\
\hline \multirow{2}{*}{$\begin{array}{l}\text { King and } \\
\text { Helpful }\end{array}$} & Teacher & $4 \%$ & $8 \%$ & $21 \%$ & $8 \%$ & $17 \%$ & $13 \%$ & $54 \%$ & $71 \%$ \\
\hline & Parent & $33 \%$ & $17 \%$ & $8 \%$ & $13 \%$ & $4 \%$ & $8 \%$ & $54 \%$ & $58 \%$ \\
\hline \multirow{2}{*}{ Impact } & Teacher & $58 \%$ & $33 \%$ & $4 \%$ & $4 \%$ & $13 \%$ & $4 \%$ & $25 \%$ & $58 \%$ \\
\hline & Parent & $63 \%$ & $17 \%$ & $17 \%$ & $0 \%$ & $4 \%$ & $29 \%$ & $17 \%$ & $54 \%$ \\
\hline \multirow{2}{*}{ Overall Stress } & Teacher & $67 \%$ & $29 \%$ & $8 \%$ & $17 \%$ & $21 \%$ & $4 \%$ & $4 \%$ & $50 \%$ \\
\hline & Parent & $42 \%$ & $21 \%$ & $8 \%$ & $13 \%$ & $13 \%$ & $13 \%$ & $38 \%$ & $54 \%$ \\
\hline
\end{tabular}

\begin{tabular}{|l|l|l|l|}
\hline Teachers & \multicolumn{4}{|l|}{ Mean Score (Standard Deviation) } \\
\hline Category & Pre & Post & General Population \\
\hline Emotional & $1.91(1.73)$ & $1.5(1.5)$ & $1(1.6)$ \\
\hline Behavioural & $5.62(2.64)$ & $2.58(2.31)$ & $0.8(1.5)$ \\
\hline Hyperactivity & $7.62(2.67)$ & $4.91(2.76)$ & $2.6(2.7)$ \\
\hline Peer problems & $5.08(2.25)$ & $3.12(1.92)$ & $1.3(1.7)$ \\
\hline Prosocial & $3.45(2.36)$ & $5.54(2.48)$ & $7.4(2.6)$ \\
\hline Parent & Mean Score (Standard Deviation) \\
\hline Category & Pre & Post & General Population \\
\hline Emotional & $3.25(2.91)$ & $2.08(2.19)$ & $1.1(1.3)$ \\
\hline Behavioural & $5.25(2.36)$ & $3.45(2.17)$ & $2(1.8)$ \\
\hline Hyperactivity & $5.75(2.94)$ & $4.66(2.47)$ & $2.9(2.3)$ \\
\hline Peer problems & $3.41(2.25)$ & $3.04(1.92)$ & $1.3(1.4)$ \\
\hline Prosocial & $6.62(1.95)$ & $7.45(2.04)$ & $8.1(1.8)$ \\
\hline
\end{tabular}




\begin{tabular}{|c|c|c|c|c|c|c|c|c|c|}
\hline \multicolumn{10}{|c|}{ Overall Stress } \\
\hline \multicolumn{5}{|c|}{ Parent } & \multicolumn{5}{|c|}{ Teacher } \\
\hline \multicolumn{2}{|c|}{ PRE } & \multicolumn{2}{|c|}{ POST } & \multirow{2}{*}{\begin{tabular}{|l} 
Diff \\
11 \\
\end{tabular}} & \multicolumn{2}{|c|}{ PRE } & \multicolumn{2}{|c|}{ POST } & \multirow{2}{*}{$\begin{array}{l}\text { Diff } \\
17 \\
\end{array}$} \\
\hline 20 & $\mathrm{VH}$ & 9 & $\mathrm{~A}$ & & 26 & $\mathrm{VH}$ & 9 & $\mathrm{~A}$ & \\
\hline 8 & $\mathrm{~A}$ & 7 & $\mathrm{~A}$ & 1 & 21 & $\mathrm{VH}$ & 10 & $\mathrm{~A}$ & 11 \\
\hline 14 & $\mathrm{SR}$ & 6 & $\mathrm{~A}$ & 8 & 13 & $\mathrm{SR}$ & 4 & $A$ & 9 \\
\hline 27 & $\mathrm{VH}$ & 18 & $\mathrm{H}$ & 9 & 26 & $\mathrm{VH}$ & 19 & $\mathrm{VH}$ & 7 \\
\hline 25 & $\mathrm{VH}$ & 12 & $\mathrm{~A}$ & 13 & 23 & $\mathrm{VH}$ & 11 & SR & 12 \\
\hline 9 & $\mathrm{~A}$ & 10 & $\mathrm{~A}$ & -1 & 8 & $\mathrm{~A}$ & 5 & $\mathrm{~A}$ & 3 \\
\hline 14 & SR & 7 & $\mathrm{~A}$ & 7 & 12 & SR & 5 & $\mathrm{~A}$ & 7 \\
\hline 22 & $\mathrm{VH}$ & 7 & $\mathrm{~A}$ & 15 & 20 & $\mathrm{VH}$ & 8 & $\mathrm{~A}$ & 12 \\
\hline 23 & $\mathrm{VH}$ & 23 & $\mathrm{VH}$ & 0 & 23 & $\mathrm{VH}$ & 17 & $\mathrm{H}$ & 6 \\
\hline 18 & $\mathrm{H}$ & 15 & $\mathrm{SR}$ & 3 & 26 & $\mathrm{VH}$ & 23 & $\mathrm{VH}$ & 3 \\
\hline 11 & $\mathrm{~A}$ & 14 & $\mathrm{SR}$ & -3 & 15 & $\mathrm{H}$ & 19 & $\mathrm{VH}$ & -4 \\
\hline 19 & $\mathrm{VH}$ & 16 & $\mathrm{H}$ & 3 & 13 & $\mathrm{SR}$ & 7 & $\mathrm{~A}$ & 6 \\
\hline 10 & $\mathrm{~A}$ & 13 & SR & -3 & 24 & $\mathrm{VH}$ & 19 & $\mathrm{VH}$ & 5 \\
\hline 11 & $\mathrm{~A}$ & 16 & $\mathrm{H}$ & -5 & 25 & $\mathrm{VH}$ & 16 & $\mathrm{VH}$ & 9 \\
\hline 35 & $\mathrm{VH}$ & 31 & $\mathrm{VH}$ & 4 & 27 & $\mathrm{VH}$ & 19 & $\mathrm{VH}$ & 8 \\
\hline 25 & $\mathrm{VH}$ & 19 & $\mathrm{VH}$ & 6 & 25 & $\mathrm{VH}$ & 18 & $\mathrm{VH}$ & 7 \\
\hline 26 & $\mathrm{VH}$ & 25 & $\mathrm{VH}$ & 1 & 19 & $\mathrm{VH}$ & 9 & $\mathrm{~A}$ & 10 \\
\hline 11 & $\mathrm{~A}$ & 12 & $\mathrm{~A}$ & -1 & 26 & $\mathrm{VH}$ & 16 & $\mathrm{H}$ & 10 \\
\hline 9 & $\mathrm{~A}$ & 6 & $\mathrm{~A}$ & 3 & 12 & SR & 8 & $\mathrm{~A}$ & 4 \\
\hline 13 & SR & 9 & A & 4 & 27 & $\mathrm{VH}$ & 9 & A & 18 \\
\hline 30 & $\mathrm{VH}$ & 21 & $\mathrm{VH}$ & 9 & 14 & SR & 8 & $\mathrm{~A}$ & 6 \\
\hline 18 & $\mathrm{H}$ & 12 & $\mathrm{~A}$ & 6 & 22 & $\mathrm{VH}$ & 17 & $\mathrm{H}$ & 5 \\
\hline 12 & $\mathrm{~A}$ & 5 & $\mathrm{~A}$ & 7 & 23 & $\mathrm{VH}$ & 0 & $\mathrm{~A}$ & 23 \\
\hline 10 & $\mathrm{~A}$ & 6 & A & 4 & 16 & $\mathrm{H}$ & 15 & $\mathrm{H}$ & 1 \\
\hline
\end{tabular}




\begin{tabular}{|c|c|c|c|c|c|c|c|c|c|}
\hline \multicolumn{10}{|c|}{ Emotional } \\
\hline \multicolumn{5}{|c|}{ Parent } & \multicolumn{5}{|c|}{ Teacher } \\
\hline \multicolumn{2}{|c|}{ PRE } & \multicolumn{2}{|c|}{ POST } & \multirow{2}{*}{$\begin{array}{c}\text { Diff } \\
1 \\
\end{array}$} & \multicolumn{2}{|c|}{ PRE } & \multicolumn{2}{|c|}{ POST } & Diff \\
\hline 1 & A & 0 & $\mathrm{~A}$ & & 1 & $\mathrm{~A}$ & 1 & $\mathrm{~A}$ & 0 \\
\hline 0 & A & 1 & $\mathrm{~A}$ & -1 & 0 & $\mathrm{~A}$ & 0 & $\mathrm{~A}$ & 0 \\
\hline 5 & $\mathrm{VH}$ & 0 & $\mathrm{~A}$ & 5 & 2 & $\mathrm{~A}$ & 0 & $\mathrm{~A}$ & 2 \\
\hline 8 & $\mathrm{VH}$ & 5 & $\mathrm{VH}$ & 3 & 3 & $\mathrm{SR}$ & 4 & $\mathrm{H}$ & -1 \\
\hline 2 & $\mathrm{~A}$ & 0 & $\mathrm{~A}$ & 2 & 0 & $\mathrm{~A}$ & 1 & $\mathrm{~A}$ & -1 \\
\hline 3 & $\mathrm{SR}$ & 4 & $\mathrm{H}$ & -1 & 2 & $\mathrm{~A}$ & 2 & $\mathrm{~A}$ & 0 \\
\hline 2 & $A$ & 0 & $\mathrm{~A}$ & 2 & 0 & $\mathrm{~A}$ & 0 & $\mathrm{~A}$ & 0 \\
\hline 5 & $\mathrm{VH}$ & 0 & $\mathrm{~A}$ & 5 & 2 & $\mathrm{~A}$ & 0 & $\mathrm{~A}$ & 2 \\
\hline 7 & $\mathrm{VH}$ & 4 & $\mathrm{H}$ & 3 & 6 & $\mathrm{VH}$ & 4 & $\mathrm{H}$ & 2 \\
\hline 6 & $\mathrm{VH}$ & 4 & $\mathrm{H}$ & 2 & 3 & $\mathrm{SR}$ & 4 & $\mathrm{H}$ & -1 \\
\hline 0 & $\mathrm{~A}$ & 3 & $\mathrm{SR}$ & -3 & 0 & $\mathrm{~A}$ & 2 & $\mathrm{~A}$ & -2 \\
\hline 4 & $\mathrm{H}$ & 3 & $\mathrm{SR}$ & 1 & 0 & $\mathrm{~A}$ & 0 & $\mathrm{~A}$ & 0 \\
\hline 0 & $\mathrm{~A}$ & 1 & $\mathrm{~A}$ & -1 & 2 & $\mathrm{~A}$ & 1 & $\mathrm{~A}$ & 1 \\
\hline 2 & $\mathrm{~A}$ & 1 & $\mathrm{~A}$ & 1 & 3 & $\mathrm{SR}$ & 4 & $\mathrm{H}$ & -1 \\
\hline 7 & $\mathrm{VH}$ & 6 & $\mathrm{VH}$ & 1 & 5 & $\mathrm{VH}$ & 3 & SR & 2 \\
\hline 4 & $\mathrm{H}$ & 1 & $\mathrm{~A}$ & 3 & 0 & A & 0 & $\mathrm{~A}$ & 0 \\
\hline 7 & $\mathrm{VH}$ & 6 & $\mathrm{VH}$ & 1 & 2 & A & 3 & SR & -1 \\
\hline 0 & $\mathrm{~A}$ & 1 & $\mathrm{~A}$ & -1 & 3 & $\mathrm{SR}$ & 2 & $\mathrm{~A}$ & 1 \\
\hline 1 & A & 0 & $\mathrm{~A}$ & 1 & 0 & $\mathrm{~A}$ & 0 & $\mathrm{~A}$ & 0 \\
\hline 2 & $A$ & 1 & $\mathrm{~A}$ & 1 & 3 & $\mathrm{SR}$ & 1 & $\mathrm{~A}$ & 2 \\
\hline 10 & $\mathrm{VH}$ & 7 & $\mathrm{VH}$ & 3 & 4 & $\mathrm{H}$ & 3 & SR & 1 \\
\hline 0 & A & 0 & $\mathrm{~A}$ & 0 & 0 & $\mathrm{~A}$ & 0 & $\mathrm{~A}$ & 0 \\
\hline 1 & $\mathrm{~A}$ & 1 & $\mathrm{~A}$ & 0 & 4 & $\mathrm{H}$ & 0 & $\mathrm{~A}$ & 4 \\
\hline 1 & $A$ & 1 & $\mathrm{~A}$ & 0 & 1 & $\mathrm{~A}$ & 1 & $\mathrm{~A}$ & 0 \\
\hline
\end{tabular}

\begin{tabular}{|c|c|c|c|c|c|c|c|c|c|}
\hline \multicolumn{10}{|c|}{ Behavioural } \\
\hline \multicolumn{5}{|c|}{ Parent } & \multicolumn{5}{|c|}{ Teacher } \\
\hline \multicolumn{2}{|c|}{ PRE } & \multicolumn{2}{|c|}{ POST } & \multirow{2}{*}{$\begin{array}{c}\text { Diff } \\
6\end{array}$} & \multicolumn{2}{|c|}{ PRE } & \multicolumn{2}{|c|}{ POST } & Diff \\
\hline 9 & $\mathrm{VH}$ & 3 & A & & 8 & $\mathrm{VH}$ & 0 & A & 8 \\
\hline 2 & $\mathrm{~A}$ & 1 & $\mathrm{~A}$ & 1 & 4 & $\mathrm{H}$ & 0 & $\mathrm{~A}$ & 4 \\
\hline 0 & $\mathrm{~A}$ & 0 & $\mathrm{~A}$ & 0 & 7 & $\mathrm{VH}$ & 2 & $\mathrm{~A}$ & 5 \\
\hline 7 & $\mathrm{VH}$ & 3 & $A$ & 4 & 9 & $\mathrm{VH}$ & 8 & $\mathrm{VH}$ & 1 \\
\hline 7 & $\mathrm{VH}$ & 3 & A & 4 & 7 & $\mathrm{VH}$ & 3 & SR & 4 \\
\hline 2 & $\mathrm{~A}$ & 1 & A & 1 & 2 & A & 1 & $\mathrm{~A}$ & 1 \\
\hline 6 & $\mathrm{VH}$ & 3 & $A$ & 3 & 5 & $\mathrm{VH}$ & 1 & $\mathrm{~A}$ & 4 \\
\hline 4 & $\mathrm{SR}$ & 1 & $\mathrm{~A}$ & 3 & 5 & $\mathrm{VH}$ & 0 & $\mathrm{~A}$ & 5 \\
\hline 5 & $\mathrm{H}$ & 6 & $\mathrm{VH}$ & -1 & 4 & $\mathrm{H}$ & 4 & $\mathrm{H}$ & 0 \\
\hline 6 & $\mathrm{VH}$ & 5 & $\mathrm{H}$ & 1 & 9 & $\mathrm{VH}$ & 6 & $\mathrm{VH}$ & 3 \\
\hline 3 & $\mathrm{~A}$ & 3 & $A$ & 0 & 2 & $\mathrm{~A}$ & 5 & $\mathrm{VH}$ & -3 \\
\hline 5 & $\mathrm{H}$ & 3 & A & 2 & 0 & A & 0 & A & 0 \\
\hline 5 & $\mathrm{H}$ & 5 & $\mathrm{H}$ & 0 & 9 & $\mathrm{VH}$ & 6 & $\mathrm{VH}$ & 3 \\
\hline 4 & $\mathrm{SR}$ & 7 & $\mathrm{VH}$ & -3 & 8 & $\mathrm{VH}$ & 4 & $\mathrm{H}$ & 4 \\
\hline 10 & $\mathrm{VH}$ & 9 & $\mathrm{VH}$ & 1 & 7 & $\mathrm{VH}$ & 4 & $\mathrm{H}$ & 3 \\
\hline 8 & $\mathrm{VH}$ & 6 & $\mathrm{VH}$ & 2 & 9 & $\mathrm{VH}$ & 5 & $\mathrm{VH}$ & 4 \\
\hline 8 & $\mathrm{VH}$ & 5 & $\mathrm{H}$ & 3 & 3 & $\mathrm{SR}$ & 2 & $\mathrm{~A}$ & 1 \\
\hline 5 & $\mathrm{H}$ & 4 & $S R$ & 1 & 6 & $\mathrm{VH}$ & 3 & $\mathrm{SR}$ & 3 \\
\hline 5 & $\mathrm{H}$ & 3 & A & 2 & 6 & $\mathrm{VH}$ & 4 & $\mathrm{H}$ & 2 \\
\hline 3 & $\mathrm{~A}$ & 1 & $\mathrm{~A}$ & 2 & 6 & $\mathrm{VH}$ & 0 & $\mathrm{~A}$ & 6 \\
\hline 8 & $\mathrm{VH}$ & 4 & SR & 4 & 2 & $\mathrm{~A}$ & 0 & $\mathrm{~A}$ & 2 \\
\hline 6 & $\mathrm{VH}$ & 4 & SR & 2 & 7 & $\mathrm{VH}$ & 3 & SR & 4 \\
\hline 3 & A & 0 & A & 3 & 8 & $\mathrm{VH}$ & 0 & A & 8 \\
\hline 5 & $\mathrm{H}$ & 3 & A & 2 & 2 & A & 1 & A & 1 \\
\hline
\end{tabular}




\begin{tabular}{|c|c|c|c|c|c|c|c|c|c|}
\hline \multicolumn{10}{|c|}{ Hyperactivity } \\
\hline \multicolumn{5}{|c|}{ Parent } & \multicolumn{5}{|c|}{ Teacher } \\
\hline \multicolumn{2}{|c|}{ PRE } & \multicolumn{2}{|c|}{ POST } & \multirow{2}{*}{$\begin{array}{c}\text { Diff } \\
3 \\
\end{array}$} & \multicolumn{2}{|c|}{ PRE } & \multicolumn{2}{|c|}{ POST } & \multirow{2}{*}{$\begin{array}{c}\text { Diff } \\
5 \\
\end{array}$} \\
\hline 9 & VH & 6 & SR & & 10 & VH & 5 & SR & \\
\hline 3 & A & 2 & $\mathrm{~A}$ & 1 & 9 & $\mathrm{VH}$ & 4 & $\mathrm{~A}$ & 5 \\
\hline 4 & A & 2 & $\mathrm{~A}$ & 2 & 2 & $\mathrm{~A}$ & 2 & $\mathrm{~A}$ & 0 \\
\hline 4 & A & 4 & $\mathrm{~A}$ & 0 & 6 & $\mathrm{SR}$ & 2 & $\mathrm{~A}$ & 4 \\
\hline 10 & $\mathrm{VH}$ & 6 & SR & 4 & 10 & $\mathrm{VH}$ & 5 & SR & 5 \\
\hline 4 & A & 3 & $\mathrm{~A}$ & 1 & 3 & $\mathrm{~A}$ & 1 & $\mathrm{~A}$ & 2 \\
\hline 3 & A & 2 & A & 1 & 5 & SR & 2 & A & 3 \\
\hline 10 & $\mathrm{VH}$ & 4 & $\mathrm{~A}$ & 6 & 9 & $\mathrm{VH}$ & 5 & SR & 4 \\
\hline 9 & $\mathrm{VH}$ & 9 & $\mathrm{VH}$ & 0 & 10 & $\mathrm{VH}$ & 9 & $\mathrm{VH}$ & 1 \\
\hline 1 & A & 1 & $\mathrm{~A}$ & 0 & 9 & $\mathrm{VH}$ & 9 & $\mathrm{VH}$ & 0 \\
\hline 7 & $\mathrm{H}$ & 7 & $\mathrm{H}$ & 0 & 10 & $\mathrm{VH}$ & 9 & $\mathrm{VH}$ & 1 \\
\hline 7 & $\mathrm{H}$ & 7 & $\mathrm{H}$ & 0 & 5 & $\mathrm{SR}$ & 2 & $\mathrm{~A}$ & 3 \\
\hline 2 & A & 2 & $\mathrm{~A}$ & 0 & 9 & $\mathrm{VH}$ & 7 & $\mathrm{H}$ & 2 \\
\hline 3 & A & 6 & SR & -3 & 7 & $\mathrm{H}$ & 4 & $\mathrm{~A}$ & 3 \\
\hline 10 & $\mathrm{VH}$ & 9 & $\mathrm{VH}$ & 1 & 10 & $\mathrm{VH}$ & 6 & SR & 4 \\
\hline 10 & $\mathrm{VH}$ & 8 & $\mathrm{VH}$ & 2 & 10 & $\mathrm{VH}$ & 8 & $\mathrm{VH}$ & 2 \\
\hline 6 & SR & 8 & $\mathrm{VH}$ & -2 & 8 & $\mathrm{VH}$ & 4 & $\mathrm{~A}$ & 4 \\
\hline 4 & A & 4 & $\mathrm{~A}$ & 0 & 10 & $\mathrm{VH}$ & 7 & $\mathrm{H}$ & 3 \\
\hline 2 & A & 2 & $\mathrm{~A}$ & 0 & 3 & $\mathrm{~A}$ & 3 & $\mathrm{~A}$ & 0 \\
\hline 4 & A & 3 & A & 1 & 10 & $\mathrm{VH}$ & 5 & SR & 5 \\
\hline 5 & A & 5 & $\mathrm{~A}$ & 0 & 3 & $\mathrm{~A}$ & 2 & $\mathrm{~A}$ & 1 \\
\hline 10 & $\mathrm{VH}$ & 7 & $\mathrm{H}$ & 3 & 10 & $\mathrm{VH}$ & 9 & $\mathrm{VH}$ & 1 \\
\hline 7 & $\mathrm{H}$ & 3 & $\mathrm{~A}$ & 4 & 7 & $\mathrm{H}$ & 0 & $\mathrm{~A}$ & 7 \\
\hline 4 & A & 2 & A & 2 & 8 & $\mathrm{VH}$ & 8 & VH & 0 \\
\hline
\end{tabular}

\begin{tabular}{|c|c|c|c|c|c|c|c|c|c|}
\hline \multicolumn{10}{|c|}{ Getting along } \\
\hline \multicolumn{5}{|c|}{ Parent } & \multicolumn{5}{|c|}{ Teacher } \\
\hline \multicolumn{2}{|c|}{ PRE } & \multicolumn{2}{|c|}{ POST } & \multirow{2}{*}{$\begin{array}{c}\text { Diff } \\
5\end{array}$} & \multicolumn{2}{|c|}{ PRE } & \multicolumn{2}{|c|}{ POST } & \multirow{2}{*}{$\begin{array}{r}\text { Dif } \\
4 \\
\end{array}$} \\
\hline 5 & $\mathrm{VH}$ & 0 & $\mathrm{~A}$ & & 7 & $\mathrm{VH}$ & 3 & SR & \\
\hline 3 & SR & 3 & $\mathrm{SR}$ & 0 & 8 & $\mathrm{VH}$ & 6 & $\mathrm{VH}$ & 2 \\
\hline 5 & $\mathrm{VH}$ & 4 & $\mathrm{H}$ & 1 & 2 & $\mathrm{~A}$ & 0 & $\mathrm{~A}$ & 2 \\
\hline 8 & $\mathrm{VH}$ & 6 & $\mathrm{VH}$ & 2 & 8 & $\mathrm{VH}$ & 5 & $\mathrm{H}$ & 3 \\
\hline 6 & $\mathrm{VH}$ & 3 & $\mathrm{SR}$ & 3 & 6 & $\mathrm{VH}$ & 2 & $\mathrm{~A}$ & 4 \\
\hline 0 & $\mathrm{~A}$ & 2 & $\mathrm{~A}$ & -2 & 1 & $\mathrm{~A}$ & 1 & $\mathrm{~A}$ & 0 \\
\hline 3 & $\mathrm{SR}$ & 2 & $\mathrm{~A}$ & 1 & 2 & $\mathrm{~A}$ & 2 & $\mathrm{~A}$ & 0 \\
\hline 3 & SR & 2 & $\mathrm{~A}$ & 1 & 4 & $\mathrm{SR}$ & 3 & SR & 1 \\
\hline 2 & $\mathrm{~A}$ & 4 & $\mathrm{H}$ & -2 & 3 & $\mathrm{SR}$ & 0 & $\mathrm{~A}$ & 3 \\
\hline 5 & $\mathrm{VH}$ & 5 & $\mathrm{VH}$ & 0 & 5 & $\mathrm{H}$ & 4 & SR & 1 \\
\hline 1 & $\mathrm{~A}$ & 1 & $\mathrm{~A}$ & 0 & 3 & $\mathrm{SR}$ & 3 & SR & 0 \\
\hline 3 & $\mathrm{SR}$ & 3 & $\mathrm{SR}$ & 0 & 8 & $\mathrm{VH}$ & 5 & $\mathrm{H}$ & 3 \\
\hline 3 & $\mathrm{SR}$ & 5 & $\mathrm{VH}$ & -2 & 4 & $\mathrm{SR}$ & 5 & $\mathrm{H}$ & -1 \\
\hline 2 & A & 2 & $\mathrm{~A}$ & 0 & 7 & $\mathrm{VH}$ & 4 & SR & 3 \\
\hline 8 & $\mathrm{VH}$ & 7 & $\mathrm{VH}$ & 1 & 5 & $\mathrm{H}$ & 6 & $\mathrm{H}$ & -1 \\
\hline 3 & SR & 4 & $\mathrm{H}$ & -1 & 6 & $\mathrm{VH}$ & 5 & $\mathrm{H}$ & 1 \\
\hline 5 & $\mathrm{VH}$ & 6 & $\mathrm{VH}$ & -1 & 6 & $\mathrm{VH}$ & 0 & $\mathrm{~A}$ & 6 \\
\hline 2 & $\mathrm{~A}$ & 2 & A & 0 & 7 & $\mathrm{VH}$ & 4 & SR & 3 \\
\hline 1 & A & 1 & $\mathrm{~A}$ & 0 & 3 & $\mathrm{SR}$ & 1 & $\mathrm{~A}$ & 2 \\
\hline 4 & $\mathrm{H}$ & 4 & $\mathrm{H}$ & 0 & 8 & $\mathrm{VH}$ & 3 & SR & 5 \\
\hline 7 & $\mathrm{VH}$ & 5 & $\mathrm{VH}$ & 2 & 5 & $\mathrm{H}$ & 3 & SR & 2 \\
\hline 2 & $\mathrm{~A}$ & 1 & A & 1 & 5 & $\mathrm{H}$ & 5 & $\mathrm{H}$ & 0 \\
\hline 1 & A & 1 & $\mathrm{~A}$ & 0 & 4 & SR & 0 & A & 4 \\
\hline 0 & $\mathrm{~A}$ & 0 & $\mathrm{~A}$ & 0 & 5 & $\mathrm{H}$ & 5 & $\mathrm{H}$ & 0 \\
\hline
\end{tabular}




\begin{tabular}{|c|c|c|c|c|c|c|c|c|c|}
\hline \multicolumn{10}{|c|}{ Kind and helpful } \\
\hline \multicolumn{5}{|c|}{ Parent } & \multicolumn{5}{|c|}{ Teacher } \\
\hline \multicolumn{2}{|c|}{ PRE } & \multicolumn{2}{|c|}{ POST } & \multirow{2}{*}{$\begin{array}{c}\text { Diff } \\
4\end{array}$} & \multicolumn{2}{|c|}{ PRE } & \multicolumn{2}{|c|}{ POST } & \multirow{2}{*}{$\begin{array}{c}\text { Diff } \\
1\end{array}$} \\
\hline 4 & $\mathrm{VH}$ & 8 & $A$ & & 6 & $A$ & 7 & $A$ & \\
\hline 7 & $A$ & 9 & $A$ & 2 & 0 & $\mathrm{VH}$ & 2 & $\mathrm{VH}$ & 2 \\
\hline 9 & $A$ & 10 & $A$ & 1 & 5 & $A$ & 10 & $A$ & 5 \\
\hline 6 & $S R$ & 10 & A & 4 & 2 & $\mathrm{VH}$ & 5 & $A$ & 3 \\
\hline 8 & $A$ & 7 & $\mathrm{~A}$ & -1 & 4 & SR & 6 & $A$ & 2 \\
\hline 10 & $\mathrm{~A}$ & 7 & $\mathrm{~A}$ & -3 & 4 & $\mathrm{SR}$ & 5 & $\mathrm{~A}$ & 1 \\
\hline 5 & $\mathrm{H}$ & 10 & $A$ & 5 & 5 & $A$ & 8 & $A$ & 3 \\
\hline 9 & $A$ & 10 & $A$ & 1 & 3 & $\mathrm{H}$ & 7 & $A$ & 4 \\
\hline 6 & $S R$ & 6 & $\mathrm{SR}$ & 0 & 4 & SR & 5 & $\mathrm{~A}$ & 1 \\
\hline 8 & $A$ & 8 & $A$ & 0 & 4 & SR & 5 & $A$ & 1 \\
\hline 8 & $\mathrm{~A}$ & 7 & $\mathrm{~A}$ & -1 & 3 & $\mathrm{H}$ & 4 & $\mathrm{SR}$ & 1 \\
\hline 8 & $A$ & 8 & A & 0 & 1 & $\mathrm{VH}$ & 6 & $A$ & 5 \\
\hline 5 & $\mathrm{H}$ & 7 & $A$ & 2 & 1 & $\mathrm{VH}$ & 3 & $\mathrm{H}$ & 2 \\
\hline 5 & $\mathrm{H}$ & 6 & SR & 1 & 3 & $\mathrm{H}$ & 3 & $\mathrm{H}$ & 0 \\
\hline 1 & $\mathrm{VH}$ & 3 & $\mathrm{VH}$ & 2 & 4 & SR & 7 & $A$ & 3 \\
\hline 6 & SR & 6 & SR & 0 & 4 & SR & 3 & $\mathrm{H}$ & -1 \\
\hline 6 & SR & 5 & $\mathrm{H}$ & -1 & 0 & $\mathrm{VH}$ & 1 & $\mathrm{VH}$ & 1 \\
\hline 7 & $A$ & 8 & A & 1 & 2 & $\mathrm{VH}$ & 5 & $A$ & 3 \\
\hline 5 & $\mathrm{H}$ & 9 & A & 4 & 4 & SR & 6 & A & 2 \\
\hline 7 & $A$ & 8 & $\mathrm{~A}$ & 1 & 0 & $\mathrm{VH}$ & 5 & $A$ & 5 \\
\hline 8 & $A$ & 3 & $\mathrm{VH}$ & -5 & 6 & $\mathrm{~A}$ & 8 & $\mathrm{~A}$ & 2 \\
\hline 5 & $\mathrm{H}$ & 5 & $\mathrm{H}$ & 0 & 1 & $\mathrm{VH}$ & 2 & $\mathrm{VH}$ & 1 \\
\hline 7 & A & 10 & A & 3 & 7 & $A$ & 10 & $A$ & 3 \\
\hline 9 & A & 9 & A & 0 & 10 & $A$ & 10 & $A$ & 0 \\
\hline
\end{tabular}

\section{Appendix I}

Breakdown of statistical analysis of SDQ mean scores for Overall stress and sub scales

Teacher Overall stress

t-Test: Paired Two Sample for Means

Variable $1 \quad$ Variable 2

Mean

Variance

20.25

12.125

Observations

34.19565

37.15761

Pearson Correlation

24

24

0.544303

Hypothesized Mean Difference

0

df

t Stat

6.976872

$\mathrm{P}(\mathrm{T}<=\mathrm{t})$ one-tail

2.06E-07

$t$ Critical one-tail

1.713872

$\mathrm{P}(\mathrm{T}<=\mathrm{t})$ two-tail

4.13E-07

t Critical two-tail

2.068658 
Teacher

t-Test: Paired Two Sample for Means

\begin{tabular}{lll}
\hline & Variable 1 & Variable 2 \\
\hline Mean & 1.916667 & 1.5 \\
Variance & 3.123188 & 2.347826 \\
Observations & 24 & 24 \\
Pearson Correlation & 0.6583 & \\
Hypothesized Mean Difference & 0 & \\
$\mathrm{df}$ & 23 & \\
$\mathrm{t}$ Stat & 1.478618 & \\
$\mathrm{P}(\mathrm{T}<=\mathrm{t})$ one-tail & 0.076404 & \\
$\mathrm{t}$ Critical one-tail & 1.713872 & \\
$\mathrm{P}(\mathrm{T}<=\mathrm{t})$ two-tail & 0.152808 & \\
$\mathrm{t}$ Critical two-tail & 2.068658 & \\
\hline
\end{tabular}

Teacher

t-Test: Paired Two Sample for Means

\begin{tabular}{lll}
\hline & Variable 1 & Variable 2 \\
\hline Mean & 5.625 & 2.583333 \\
Variance & 7.288043 & 5.557971 \\
Observations & 24 & 24 \\
Pearson Correlation & 0.514061 & \\
Hypothesized Mean Difference & 0 & \\
$\mathrm{df}$ & 23 & \\
$\mathrm{t}$ Stat & 5.935531 & \\
$\mathrm{P}(\mathrm{T}<=\mathrm{t})$ one-tail & $2.37 \mathrm{E}-06$ & \\
$\mathrm{t}$ Critical one-tail & 1.713872 & \\
$\mathrm{P}(\mathrm{T}<=\mathrm{t})$ two-tail & $4.74 \mathrm{E}-06$ & \\
$\mathrm{t}$ Critical two-tail & 2.068658 \\
\hline
\end{tabular}


Teacher

t-Test: Paired Two Sample for Means

\begin{tabular}{lll}
\hline & Variable 1 & Variable 2 \\
\hline Mean & 7.625 & 4.916667 \\
Variance & 7.461957 & 7.992754 \\
Observations & 24 & 24 \\
Pearson Correlation & 0.750179 & \\
Hypothesized Mean Difference & 0 & \\
$\mathrm{df}$ & 23 & \\
$\mathrm{t}$ Stat & 6.746497 & \\
$\mathrm{P}(\mathrm{T}<=\mathrm{t})$ one-tail & $3.5 \mathrm{E}-07$ & \\
$\mathrm{t}$ Critical one-tail & 1.713872 & \\
$\mathrm{P}(\mathrm{T}<=\mathrm{t})$ two-tail & $7 \mathrm{E}-07$ & \\
$\mathrm{t} \mathrm{Critical} \mathrm{two-tail}$ & 2.068658 \\
\hline
\end{tabular}

Teacher

t-Test: Paired Two Sample for Means

\begin{tabular}{lll}
\hline & Variable 1 & Variable 2 \\
\hline Mean & 5.083333 & 3.125 \\
Variance & 4.34058 & 3.940217 \\
Observations & 24 & 24 \\
Pearson Correlation & $\# \mathrm{~N} / \mathrm{A}$ & \\
Hypothesized Mean Difference & 0 & \\
$\mathrm{df}$ & 23 & \\
$\mathrm{t}$ Stat & 5.051567 \\
$\mathrm{P}(\mathrm{T}<=\mathrm{t})$ one-tail & $2.05 \mathrm{E}-05$ \\
$\mathrm{t}$ Critical one-tail & 1.713872 \\
$\mathrm{P}(\mathrm{T}<=\mathrm{t})$ two-tail & $4.1 \mathrm{E}-05$ & \\
$\mathrm{t} \mathrm{Critical} \mathrm{two-tail}$ & 2.068658 \\
\hline
\end{tabular}


Teacher

t-Test: Paired Two Sample for Means

\begin{tabular}{lll}
\hline & Variable 1 & Variable 2 \\
\hline Mean & 3.458333 & 5.541667 \\
Variance & 5.824275 & 6.432971 \\
Observations & 24 & 24 \\
Pearson Correlation & 0.788736 & \\
Hypothesized Mean Difference & 0 & \\
$\mathrm{df}$ & 23 & \\
$\mathrm{t}$ Stat & -6.32786 & \\
$\mathrm{P}(\mathrm{T}<=\mathrm{t})$ one-tail & $9.3 \mathrm{E}-07$ & \\
$\mathrm{t}$ Critical one-tail & 1.713872 & \\
$\mathrm{P}(\mathrm{T}<=\mathrm{t})$ two-tail & $1.86 \mathrm{E}-06$ & \\
$\mathrm{t} \mathrm{Critical} \mathrm{two-tail}$ & 2.068658 & \\
\hline
\end{tabular}

\section{Copyrights}

Copyright for this article is retained by the author(s), with first publication rights granted to the journal.

This is an open-access article distributed under the terms and conditions of the Creative Commons Attribution license (http://creativecommons.org/licenses/by/4.0/). 